\title{
Silver Nanoparticles for Conductive Inks: From Synthesis and Ink Formulation to Their Use in Printing Technologies
}

\author{
Junhui Zhang ${ }^{1,2}\left(\right.$, Maziar Ahmadi ${ }^{1,2}$, Gemma Fargas ${ }^{1,2, *} \mathbb{C}$, Nikola Perinka ${ }^{3}$, Javier Reguera ${ }^{3}(\mathbb{D}$, \\ Senentxu Lanceros-Méndez ${ }^{3,4}\left(\mathbb{D}\right.$, Luis Llanes ${ }^{1,2, *}$ and Emilio Jiménez-Piqué ${ }^{1,2} \mathbb{C}$
}

check for

updates

Citation: Zhang, J.; Ahmadi, M.; Fargas, G.; Perinka, N.; Reguera, J.; Lanceros-Méndez, S.; Llanes, L.; Jiménez-Piqué, E. Silver Nanoparticles for Conductive Inks: From Synthesis and Ink Formulation to Their Use in Printing Technologies. Metals 2022, 12, 234. https:// doi.org/10.3390/met12020234

Academic Editor: Leonid M. Kustov

Received: 15 December 2021

Accepted: 21 January 2022

Published: 26 January 2022

Publisher's Note: MDPI stays neutral with regard to jurisdictional claims in published maps and institutional affiliations.

Copyright: (C) 2022 by the authors. Licensee MDPI, Basel, Switzerland. This article is an open access article distributed under the terms and conditions of the Creative Commons Attribution (CC BY) license (https:// creativecommons.org/licenses/by/ $4.0 /)$.
1 CIEFMA-Departament de Ciència i Enginyeria de Materials, Campus Diagonal Besòs (EEBE), Universitat Politècnica de Catalunya, C/Eduard Maristany, 10-14, Building I, 1st Floor, 08019 Barcelona, Spain; junhui.zhang@upc.edu (J.Z.); maziar.ahmadi@upc.edu (M.A.); emilio.jimenez@upc.edu (E.J.-P.)

2 Barcelona Research Center for Multiscale Science and Engineering, Campus Diagonal Besòs (EEBE), Universitat Politècnica de Catalunya, C/Eduard Maristany, 10-14, Building I, Basement Floor, 08019 Barcelona, Spain

3 BCMaterials, Basque Center for Materials, Applications, and Nanostructures, UPV /EHU Science Park, 48940 Leioa, Spain; nikola.perinka@bcmaterials.net (N.P.); javier.reguera@bcmaterials.net (J.R.); senentxu.lanceros@bcmaterials.net (S.L.-M.)

4 IKERBASQUE, Basque Foundation for Science, 48009 Bilbao, Spain

* Correspondence: gemma.fargas@upc.edu (G.F.); luis.miguel.llanes@upc.edu (L.L.)

\begin{abstract}
Currently, silver nanoparticles have attracted large interest in the photonics, electrics, analytical, and antimicrobial/biocidal fields due to their excellent optical, electrical, biological, and antibacterial properties. The versatility in generating different sizes, shapes, and surface morphologies results in a wide range of applications of silver nanoparticles in various industrial and health-related areas. In industrial applications, silver nanoparticles are used to produce conductive inks, which allows the construction of electronic devices on low-cost and flexible substrates by using various printing techniques. In order to achieve successful printed patterns, the necessary formulation and synthesis need to be engineered to fulfil the printing technique requirements. Additional sintering processes are typically further required to remove the added polymers, which are used to produce the desired adherence, viscosity, and reliable performance. This contribution presents a review of the synthesis of silver nanoparticles via different methods (chemical, physical and biological methods) and the application of silver nanoparticles under the electrical field. Formulation of silver inks and formation of conductive patterns by using different printing techniques (inkjet printing, screen printing and aerosol jet printing) are presented. Post-printing treatments are also discussed. A summary concerning outlooks and perspectives is presented at the end of this review.
\end{abstract}

Keywords: silver nanoparticles; synthesis; silver-based ink formulations; post-printing treatments

\section{Introduction}

Nanoparticles, defined as having one of the dimensions in the 1-100 nm range [1], show unique and considerably different physical, chemical, and biological properties, compared to bulk materials, due to their large portion of surface atoms and the reduced area to volume ratio. For many of them, enhanced reactivity and unique optical, electronic, and magnetic properties are observed [2].

Among various nanoparticle materials, silver nanoparticles (Ag NPs) have gained an enormous relevance due to their high electrical conductivity, low cost with respect to gold, relative resistance to oxidation, and biocidal properties [3,4]. Currently, many methods and approaches have been developed to synthesize Ag NPs, including chemical, physical, and biological routes, with the chemical methods being the most investigated and versatile. Physical methods, while producing nanoparticles with cleaner surfaces, are highly energy-intensive [5]. Biological synthesis has more advantages than the others. It 
appears as a cost-effective and environmentally stable approach, but with higher limits in the reagents range and, therefore, on the morphological control. In this review, we try to bring out the possible ways that were successful in synthesizing Ag NPs for their use as fillers in the development of conductive inks.

In recent years, printed electronic devices have acquired great interest due to their lowcost high-volume manufacturing [6,7]. Compared with traditional production processes, such as evaporation, sputtering and chemical vapor deposition, which require complicated manufacturing processes and relatively high-cost equipment, printing technologies can bring competitive advantages in terms of product cost and flexibility, and performance [8,9]. There are a variety of printing technologies, including gravure printing, stereolithography, inkjet printing, screen printing, and aerosol jet printing. Each of these printing technologies has its advantages and disadvantages. The type of ink formulation and substrate plays an important role in determining the printing methods. In this review, three printing technologies (inkjet printing, screen printing and aerosol jet printing) are discussed.

Currently, silver-based inks are used in micro- or nano-electronic industries by printing technologies in a broad set of applications, such as sensors [10-12], solar cells [13,14], thinfilm transistors [15], or supercapacitors [16,17]. The typical inks used for printing methods contain functional particles (e.g., Ag NPs), binders, solvents, and additives. Among these, functional particles, Ag NPs, are the main and the most important component. Ag NPs provide the electronic properties of the printed patterns. In general, the higher Ag NPs loading, the higher conductivity of printed patterns, and the conductive inks contain the solid loadings ranging from 20 to $80 \mathrm{wt. \%}$ [8]. In the case of Ag NPs inks, the size, shape, uniformity, and purity of Ag NPs determine the properties of the resulting products and should be considered to generate the final formulation and avoid undesired processing difficulties. The binder is often added into silver inks that helps in the homogeneous dispersion of Ag NPs into the ink. In addition, proper adhesion between printed patterns and substrates can be achieved by using the binder [18]. Solvents used as carriers for Ag NPs allow the ink to flow and impart favorable viscosity, surface tension, and homogeneity. A small quantity of additive is added to silver ink formulation and improves the property and performance of the ink. Generally, various additives, such as rheology modifiers, deformers, thickeners, and plasticizers, may be added to ink formulations, depending on the desired performance [19]. These components are coordinated together to the optimization of printing performance and quality of the printed patterns [20]. For instance, a not wellformulated ink could result in clogging of printer nozzles because of agglomeration or sedimentation of nanoparticles. The nanoparticles are then limited to a range of particle size and high colloidal stability to flow through the nozzles [8,21]. Alternatively, to solve the above issues, reactive silver inks have been proposed as a low-cost and promising solution for fabricating highly conductive silver tracks [22]. In the reactive inks, silver is a complex ion dissolved in an aqueous system, and low-temperature evaporation of complex ligands is sufficient for precipitating silver and reducing it to bulk silver for creating conductive patterns $[23,24]$.

Physicochemical properties, such as viscosity, surface tension, evaporation rate and adhesion to substrates, are also very critically important to achieve high printing accuracy and resolution. The viscosity of conductive ink shows the behavior of its resistance to flow, and surface tension results from intermolecular forces that exist in liquids. For example, during the inkjet printing process, surface tension has an important effect on the formation of droplets. Higher surface tension values would result in earlier droplet breakup and faster drop velocity [25]. The viscosity and surface tension of conductive inks should be located in suitable ranges to meet the requirements of different printing technologies, which are presented later. The drying process removes moisture and/or solvents after the ink is transferred to the substrate without a significant increase in substrate temperature. The drying process imparts the proper adhesion of the ink to the substrate. There are many drying mechanisms, such as evaporation of water and/or solvent, penetration into the 
printing substrate and air oxidation. Some inks combine two or more drying mechanisms during the drying process $[26,27]$.

Polymers are relevant in ink formulations to promote good dispersion and avoid agglomeration, especially in metal-based nanoparticle inks. However, in order to produce highly conductive patterns, the dielectric polymer phase should be removed by sintering treatments [28].

Here, we will review the different methods to obtain Ag NPs, their use in the preparation of stable dispersion of inks depending on the printing method, and the post-processing of printed patterns for obtaining high electrical conductivity, as shown in Figure 1.

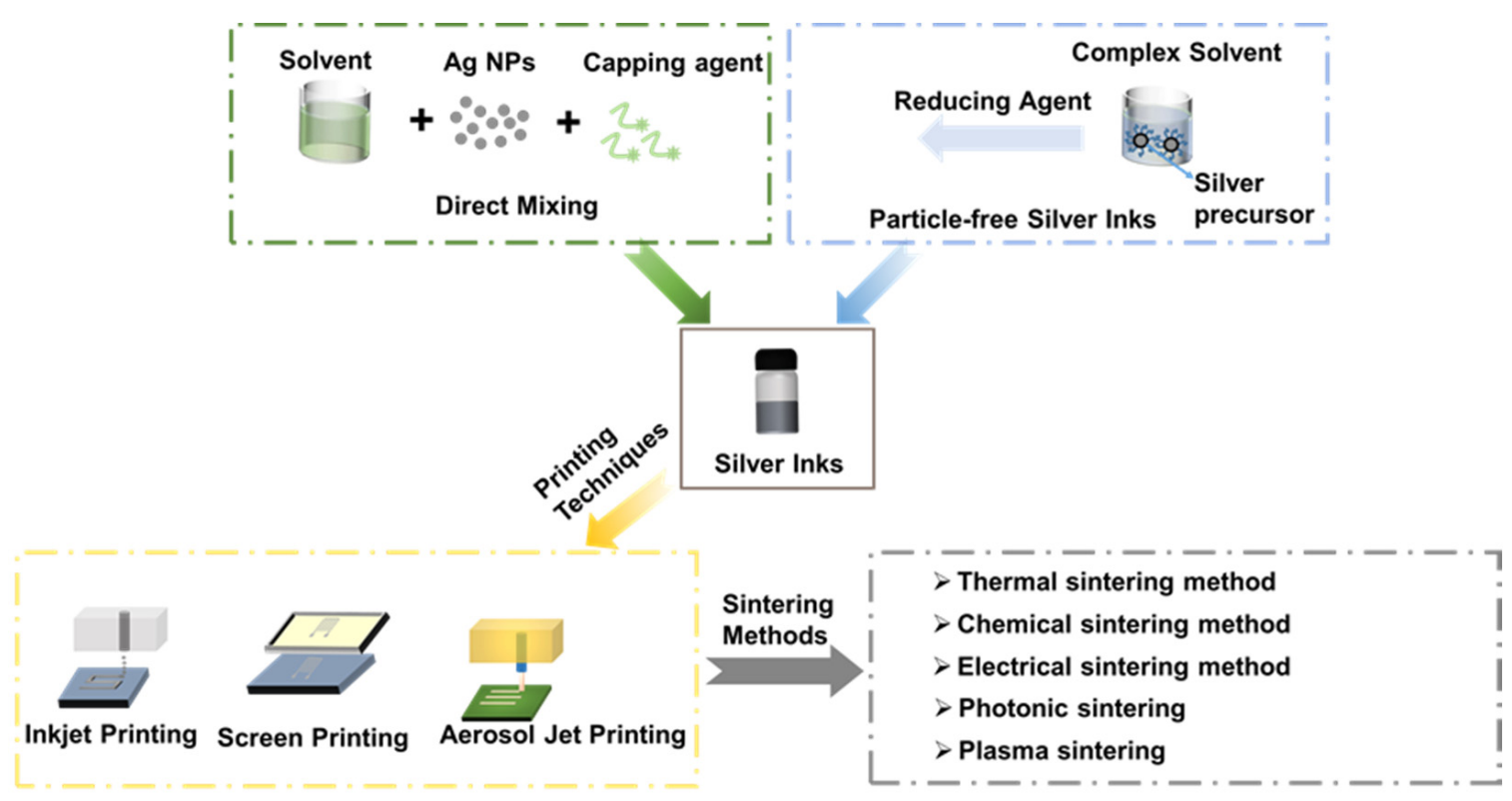

Figure 1. Preparation of silver inks, different printing techniques and sintering methods.

\section{Synthesis of Ag NPs}

The size, shape, uniformity, and stability, as well as the corresponding physical, chemical, and biological properties of nanoparticles, are strongly dependent on synthetic methods [2]. A variety of methodologies are employed to synthesize Ag NPs, generally classified in chemical, physical, and biological methods [29]. The different methods are described in the following sections.

\subsection{Synthesis of Ag NPs by Chemical Methods}

Chemical methods are the most extensively investigated route for developing Ag NPs. The chemical methods can be divided into four different categories: (1) chemical reduction, (2) electrochemical techniques, (3) pyrolysis, and (4) irradiation-assisted methods [30]. Among these methods, the chemical reduction of $\mathrm{Ag}^{+}$species to $\mathrm{Ag}^{0}$ in solution using reducing agents is the most common and widely reported synthesis method of Ag NPs, usually no aggregation, high yield, and low preparation cost [29].

The formation mechanism of nanoparticles from solutions has been investigated, including nucleation and growth process [31]. The nucleation process requires more activation energy than the growth process, which is controlled by diffusion. The relative rates of nucleation and growth process are governed by varying reaction parameters, such as concentration of the reactants, the potency of the reducing agent, $\mathrm{pH}$, or temperature. These parameters can be adjusted to fine-tune the nanoparticle synthesis achieving a single nucleation step and a steady growth process following a typical formation pattern of a LaMer model [32]. Figure 2 shows a plot of the LaMer model in which the monomer concentration is shown as a function of time [33]. In Stage I, the concentration of free monomers in solution increases sharply until a supersaturation $\left(C_{s}\right)$ point is obtained. The 
concentration of monomer is high enough to overcome the energy barrier for nucleation. In Stage II, burst nucleation leads to a significant decrease of the monomer concentration in solution, which reaches below the level of minimum supersaturation $\left(C_{\min }\right)$, where no additional nucleation occurs. In Stage III, growth continues without further nucleation to form nanocrystals. The separation of nucleation and growth process gives rise to identical growing times of all the nanoparticles, and therefore, uniformity in sizes. As an alternative to this synthesis, a very high uniformity can be achieved using seed-mediated-growth synthesis instead of seedless synthesis. Small nanoparticles, seeds, are added to a growing solution and act as the nucleus for continuous growth. The reduction kinetics, in this case, is maintained to be slow enough not to achieve saturation.

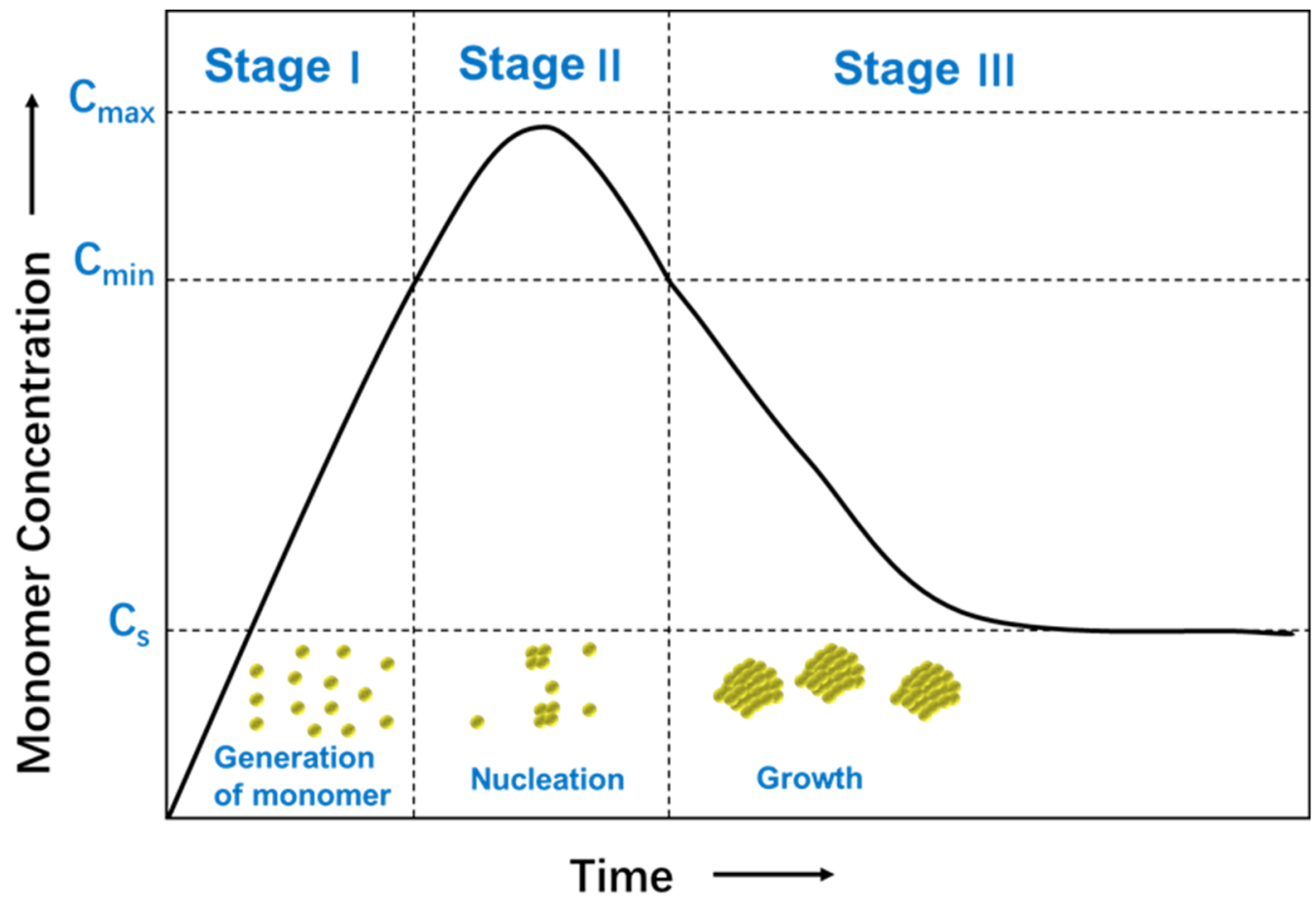

Figure 2. Schematic illustration of the LaMer model for the generation of monomers, nucleation, and subsequent growth.

The chemical reduction method usually involves three main components, i.e., metal precursors, reducing agents, and stabilizing/capping agents [34]. Different reducing agents, such as sodium citrate, ascorbate, sodium borohydride $\left(\mathrm{NaBH}_{4}\right)$, elemental hydrogen, polyol, Tollen's reagent, N, N-dimethylformamide (DMF), or polyethylene glycol (PEG)block copolymers, are used. The choice of reducing agents and solvents gives rise to a different type of synthesis and offers an enormous number of possibilities.

Among the various possibilities, Turkevich's and Brust's methods, using citrate and $\mathrm{NaBH}_{4}$, are the most used ones and generate very different nanoparticles in terms of sizes and solvent solubility [35,36]. Together with the choice of metal salt, reduction agent, and experimental factors, the capping agent is the main factor in determining the size and physicochemical properties of the nanoparticles [37]. This capping provides colloidal stability to the nanoparticle, either electrostatically or sterically, and controls the nanoparticle growth due to interactions with different facets, generating different morphologies. Capping agents contain polymers, such as poly (N-vinyl-2-pyrrolidone) (PVP), PEG, polymethacrylic acid (PMAA) and polymethylmethacrylate (PMMA) or small molecules such as citrate, oleilamine, alkanethiols, etc. Different morphologies (nanospheres [38], nanorods [39], nanocubes [40], nanodisks [41], nanoprims/nanotriangles [42], truncated octahedron [43], nanobipyramids [44], nanoshells [45,46], nanobars [47], nanorice [47], nanowires [48] and nanostars [49]) have been achieved by selecting capping agents and 
controlling experimental parameters, as shown in Figure 3. The nanoparticle shape controls, among others, the plasmonic modes and offers the possibility to manipulate and respond to a light stimulus that goes from $400 \mathrm{~nm}$ to the middle infrared [50,51]. The morphology is also relevant in their catalytic activity and the creation of electrical paths in conductive composites and inks, where high aspect ratio morphologies are preferred.

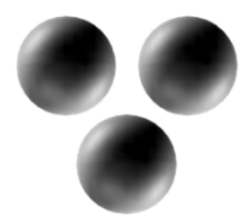

Nanospheres

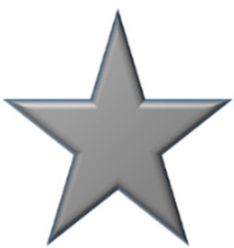

Nanostars
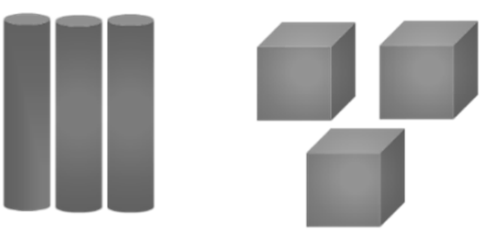

Nanorods

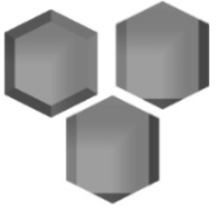

\section{Truncated Octahedron}

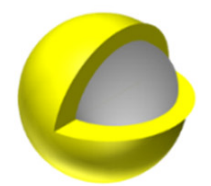

Nanoshells
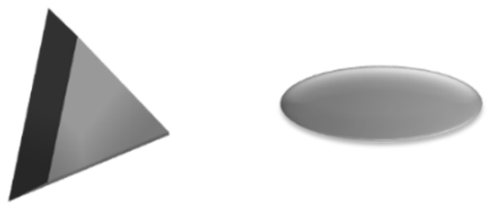

Nanotriangles

Nanorice
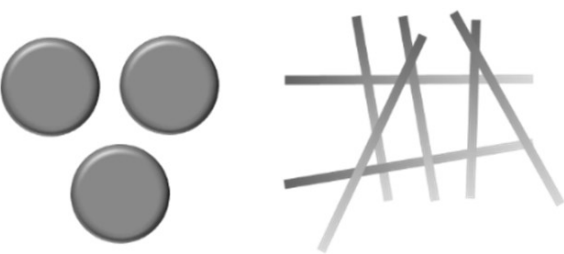

Nanodisks
Nanowires

Figure 3. Ag NPs with different shapes.

The synthesis parameters (reaction temperature, $\mathrm{pH}$ of precursors, reducers and stabilizing agents) are crucial factors in determining nanoparticles formation and nucleation process. Many different examples of Ag NPs synthesis were proposed. Wiley et al. [52] obtained Ag NPs with three different shapes (nanocubes, bipyramids, nanowires) using ethylene glycol as a reducing agent. In their experiment, PVP was added as a stabilizing agent and reducing agent, which also played a role in controlling the shape. In addition, during the reaction, the seeds with district crystal structures were selected via etching, which produced the different morphologies of Ag NPs. Xue et al. [53] reported pH-switchable silver nanoprism growth pathways. They found that excellent control over the growth of Ag nanoprisms can be achieved by adjusting solution $\mathrm{pH}$. Jiang et al. [54] investigated the reaction temperature effect on the formation and growth of Ag NPs using two or three reducing agents, including citric acid, L-ascorbic acid, and $\mathrm{NaBH}_{4}$. They found that there was a significant jump in the particle size at around $32{ }^{\circ} \mathrm{C}$. The size of plates increases from 90 to $180 \mathrm{~nm}$ and from 25 to $48 \mathrm{~nm}$ for spheres. Yoo et al. [55] synthesized Ag NPs via hydrazine reduction of Tollen's reagent. In their work, $\mathrm{AgCl}$ and ammonium hydroxide were mixed in the presence of PVP as a stabilizer, resulting in a clear solution without any precipitate. Then, hydrazine hydrate was injected to reduce $\left[\mathrm{Ag}\left(\mathrm{NH}_{3}\right)_{2}\right]^{+}$and obtain $\mathrm{Ag}$ NPs at room temperature. The size of the obtained Ag NPs was controlled by the concentration of PVP. The diameter of Ag NPs ranged from 68 to $119 \mathrm{~nm}$. In addition, $\mathrm{AgCl}$ was retrieved from the electronic scrap and used as a metal precursor. Zhang et al. [56] prepared colloid Ag NPs by using hyperbranched poly(methylene bisacrylamide-aminoethyl piperazine) with terminal dimethylamine groups (HPAMAM-N $\left.\left(\mathrm{CH}_{3}\right)_{2}\right)$ as the effective reducing and stabilizing agent. The Ag NPs were synthesized by mixing $\mathrm{AgNO}_{3}$ aqueous solution with HPAMAM-N $\left(\mathrm{CH}_{3}\right)_{2}$ aqueous solution at room temperature. A series of Ag NPs was prepared by adjusting the molar ratio of N/Ag in feed. Malassis et al. [57] used one-step aqueous synthesis of Ag NPs using ascorbic acid (vitamin C) as a reducing and stabilizing agent at the same time. Metal precursor, $\mathrm{AgNO}_{3}$, is mixed with ascorbic acid 
under a strong stirring at room temperature for $30 \mathrm{~s}$. The authors showed that the size of $\mathrm{Ag}$ NPs obtained in the range of 20 to $175 \mathrm{~nm}$ was affected by the $\mathrm{pH}$ of either the metal salt solution or the ascorbic acid solution. Leng et al. [58] produced Ag NPs by the reduction of $\mathrm{AgNO}_{3}$ using the ethylene glycol in the presence of PVP. They also studied the different reaction conditions (i.e., $\mathrm{AgNO}_{3}$ concentration, $\mathrm{AgNO}_{3}$ and $\mathrm{PVP}$ mass ratio and the reaction temperature) on the size and size distribution of Ag NPs. When the mass ratio of $\mathrm{AgNO}_{3}$ to PVP was 2:1, $\mathrm{Ag}$ NPs with a narrow size distribution from $20 \mathrm{~nm}$ to $30 \mathrm{~nm}$ were obtained. Sakthivel et al. [59] prepared isonicotinic acid hydrazide capped Ag NPs by the wet chemical method and used $\mathrm{NaBH}_{4}$ as a reducing agent. The synthesized Ag NPs distributed in two ranges and the average size of the particles is 35 and $536 \mathrm{~nm}$. Isonicotinic acid hydrazide capped $\mathrm{Ag}$ NPs were applied to detect $\mathrm{Hg}^{2+}$ in an aqueous medium in the nanomolar range. Sreelekha et al. [60] synthesized Ag NPs using trisodium citrate as reducing and stabilizing agents via the chemical method. As described in their work, Ag NPs were prepared by mixing the trisodium citrate solution and $\mathrm{AgNO}_{3}$ solution at a temperature of about $80^{\circ} \mathrm{C}$, followed by separation of the NPs by centrifugation and drying to collect. Kamarudin et al. [61] fabricated two types of Ag NPs by varying the amount of precursor and synthesis temperature. The higher reaction temperature, the higher reaction rate, which increased the process of ions to NPs conversion.

Waqas et al. [62], for instance, successfully fabricated Ag NPs with three different shapes (i.e., spherical, star and pyramidal) via a simple wet chemical approach. An aqueous solution containing silver nitrate $\left(\mathrm{AgNO}_{3}\right)$, sodium hydroxide, oleic acid, and ammonia was used in their synthesis. During the reaction, the concentration of sodium hydroxide and oleic acid played an essential role in controlling the size, shape, and homogeneity of Ag NPs. Among all the three shapes, Ag NPs with star shape showed the highest electrocatalytic sensing efficacy in terms of linear range, the limit of detection, and sensitivity, because of more exposed catalytic active sites and fast diffusion of ions between electrode-electrolyte interfaces.

Meanwhile, Makwana et al. [63] successfully prepared fluorescent Ag NPs by only applying a single chemical regent calix [4] resorcinarene polyhydrazide $(\mathrm{CPH})$ which acted as a reduction and dispersant agent. Bearing hydrazide group of $\mathrm{CPH}$ on its periphery acted as a reducing agent, and its web type of structure as a stabilizing agent for the formation of calix-protected Ag NPs. Their results showed a large quantity of well-dispersed spherical $\mathrm{CPH}-\mathrm{Ag}$ NPs with an average diameter of $7 \mathrm{~nm}$. In addition, $\mathrm{CPH}-\mathrm{Ag}$ NPs were not only selective and sensitive fluorescent sensors for $\mathrm{Fe}^{3+}$ from 0.1 to $10 \mu \mathrm{M}$ but also exhibited reasonably good antimicrobial activity.

Bare Ag NPs are not stable and can rapidly undergo agglomeration due to their high reactivity. In most of the preparation routes, capping agents are required to control the particle size, from absorbing or attaching with each other surfaces and avoiding the aggregation of nanoparticles; coating is a way to produce electrostatic, steric or electrosteric interactions between particles and helps stabilize the nanoparticles $[64,65]$. Conversely, the capping agents often influence various properties of nanoparticles, including their shape and interactions with surrounding solvent, therefore, its dispersibility and size [37]. For instance, Ajitha et al. [37] investigated the influences of capping agents (PEG, ethylenediaminetetraacetic acid (EDTA), PVP, and polyvinyl alcohol (PVA)) on Ag NPs using a simple chemical reduction method. As described in their research, the average particle size was the largest for the PEG-capped NPs with a diameter of $44 \mathrm{~nm}$ and the smallest for the PVA-capped ones with a diameter of $27 \mathrm{~nm}$. In addition, the PVA-capped ones were observed to be the most stable and to display the highest antibacterial activity. Other examples for the synthesis of Ag NPs by chemical methods are given in Table 1. 
Table 1. Synthesis of Ag NPs using chemical methods.

\begin{tabular}{|c|c|c|c|c|c|}
\hline Precursor & Reducing Agent & Stabilizer Agent & Size & Structure/Shape & Reference \\
\hline $\mathrm{AgNO}_{3}$ & Gallic acid & Gallic acid & $89 \mathrm{~nm}$ & Pseudospherical & {$[66]$} \\
\hline $\mathrm{AgNO}_{3}$ & $\mathrm{NaBH}_{4}$ & $\begin{array}{c}\text { Tartrate, citrate } \\
\text { and PVP }\end{array}$ & $118 \pm 18 \mathrm{~nm}$ & Tetrahedral & [67] \\
\hline $\mathrm{AgNO}_{3}$ & $\begin{array}{l}\text { Hydrazine hydrate } \\
\text { and sodium citrate }\end{array}$ & $\begin{array}{l}\text { Sodium dodecyl } \\
\text { sulfate }\end{array}$ & $40-60 \mathrm{~nm}$ & Spherical & [68] \\
\hline $\mathrm{AgNO}_{3}$ & $\begin{array}{l}\text { Sodium citrate and } \\
\text { tannic acid }\end{array}$ & PVP & $10-200 \mathrm{~nm}$ & Spherical & [69] \\
\hline$\left[\mathrm{Ag}\left(\mathrm{NH}_{3}\right)_{2}\right]^{+}$ & Ascorbic acid & Citrate & $40-300 \mathrm{~nm}$ & Spherical & {$[70]$} \\
\hline $\mathrm{AgNO}_{3}$ & Hydrazine hydrate & PVP & $300 \mathrm{~nm}$ & Spherical & [71] \\
\hline $\mathrm{AgNO}_{3}$ & Hydrazine & Trisodium citrate & $35 \mathrm{~nm}$ & FCC and spherical & [72] \\
\hline $\mathrm{AgNO}_{3}$ & Sodium citrate & PEG & $50 \pm 19 \mathrm{~nm}$ & $\begin{array}{l}\text { Spherical, triangular } \\
\text { and rod }\end{array}$ & {$[73]$} \\
\hline $\mathrm{AgNO}_{3}$ & Dextran & Dextran & $15 \mathrm{~nm}$ & Spherical & {$[74]$} \\
\hline $\mathrm{AgNO}_{3}$ & Ascorbic acid & Surfactin & $15-35 \mathrm{~nm}$ & Spherical & {$[75]$} \\
\hline $\mathrm{AgNO}_{3}$ & $\mathrm{NaBH}_{4}$ & PVP & $1-75 \mathrm{~nm}$ & FCC & {$[76]$} \\
\hline $\mathrm{AgNO}_{3}$ & Plasma & Trisodium citrate & $35-100 \mathrm{~nm}$ & FCC and spherical & {$[77]$} \\
\hline $\mathrm{AgNO}_{3}$ & Sodium citrate & Sodium citrate & $20-60 \mathrm{~nm}$ & Spherical & {$[78]$} \\
\hline $\mathrm{AgNO}_{3}$ & $\mathrm{NaBH}_{4}$ & Chitosan & $10-100 \mathrm{~nm}$ & Spherical & [79] \\
\hline $\mathrm{AgNO}_{3}$ & $\mathrm{NaBH}_{4}$ & Sodium citrate & $60 \mathrm{~nm}$ & Spherical & [80] \\
\hline
\end{tabular}

\subsection{Synthesis of Ag NPs by Physical Methods}

Physical methods usually are fast, do not involve toxic chemicals, and form a relatively narrow distribution of the synthesized Ag NPs size. However, they present several disadvantages compared with chemical methods, such as less control on the nanoparticle morphologies, more significant difficulties for the scaling and the requirement of more sophisticated equipment during the synthesis process. There are several different physical methods to synthesize Ag NPs, such as evaporation-condensation [30], ball milling [81], arc discharge [82], laser ablation [83], and pulsed wire evaporation (PWE) [84]. Other examples for the synthesis of Ag NPs by physical methods are given in Table 2.

Table 2. Synthesis of Ag NPs using physical methods.

\begin{tabular}{ccccc}
\hline Physical Method & Medium & Size & Structure/Shape & Reference \\
\hline PWE & Deionized Water & $<100 \mathrm{~nm}$ & Spherical & {$[84]$} \\
\hline Laser ablation & Deionized Water & $7 \pm 3 \mathrm{~nm}$ & Spherical & {$[85]$} \\
\hline Arc Discharge & Ethanol & $\approx 20 \mathrm{~nm}$ & Spherical & {$[86]$} \\
\hline Laser ablation & Deionized Water & $15 \mathrm{~nm}$ & Spherical & {$[87]$} \\
\hline Laser ablation & Deionized Water & $21 \mathrm{~nm}$ & $\begin{array}{c}\text { FCC and } \\
\text { semi-spherical }\end{array}$ & {$[88]$} \\
\hline Laser ablation & Methanol & $26 \pm 5 \mathrm{~nm}$ & $\begin{array}{l}\text { FCC and } \\
\text { spherical }\end{array}$ & {$[89]$} \\
\hline
\end{tabular}

The PWE method is known as a one-step synthetic technique to obtain nanoparticles through evaporation and condensation processes with high efficiency and high production rate [90], as shown in Figure 4. In the PWE method, electrical energy with a high voltage and high electric current is applied through a thin metallic wire, resulting in the heat and evaporation of the thin wire. Then, nanoparticles can be obtained by condensation through 
a peripheral cooling gas or liquid. The product mass and size of nanoparticles can be controlled by changing the wire explosion number, voltage, and current [84].

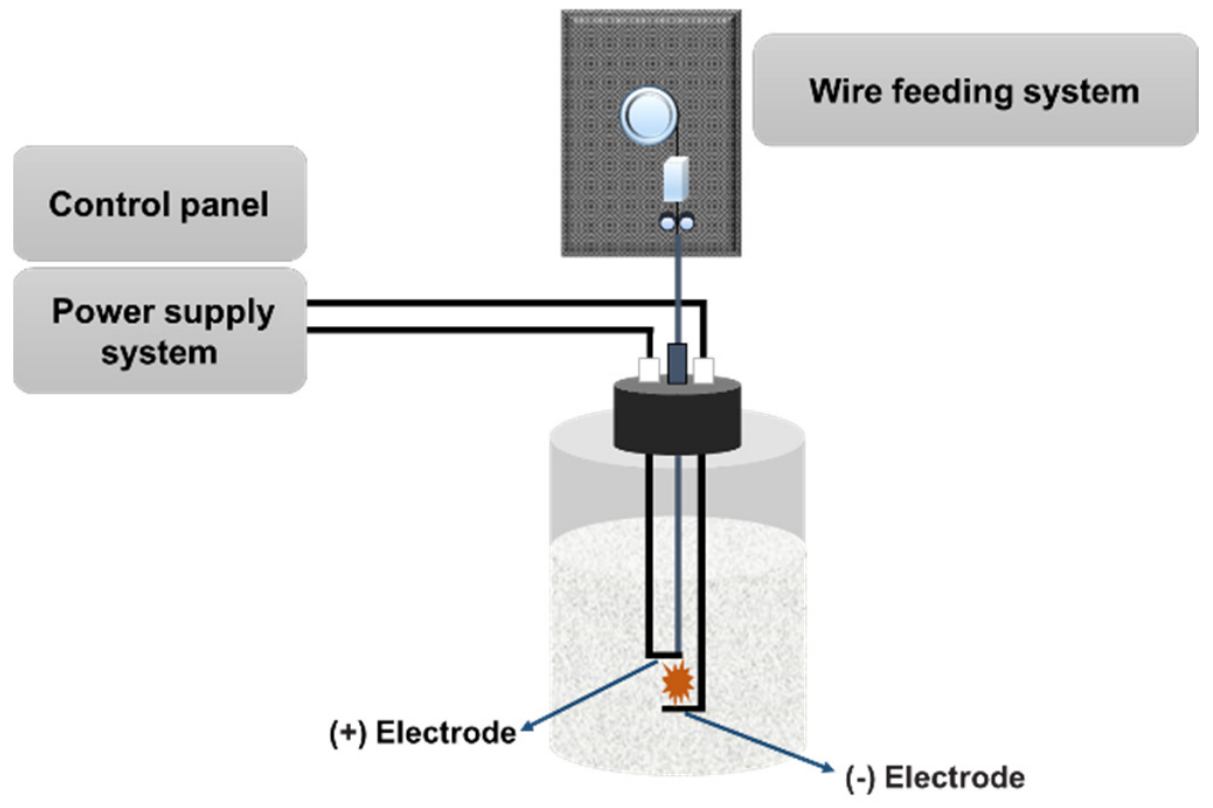

Figure 4. Schematic of PWE. In this technique, a high voltage is applied at the tip of the wire in a liquid solution, generating nanoparticles after evaporation and condensation.

Song et al. [91] investigated the effect of variation in voltage on the morphology and microstructure of Ag NPs synthesized by PWE. The average particle size increased by increasing the supply voltage without any impurity and oxide phase. The obtained Ag NPs exhibited an almost spherical shape and very small particle size (less than $30 \mathrm{~nm}$ ). In addition, Chung et al. [92] fabricated silver/copper combined nanoparticles by one-step electrical explosion of metal wires. The silver/copper nano inks were printed on flexible polyimide (PI) and sintered via the flash white light process. The sintered films show a lower resistivity $(4.06 \mu \Omega \cdot \mathrm{cm})$ and oxidation stability than the copper nanoparticle film.

\subsection{Synthesis of Ag NPs by Biological Methods}

The drawbacks with the chemical and physical methods of Ag NPs formation are that they are highly costly and involve the use of toxic and hazardous chemicals. They contain potential environmental and biological hazards [93]. Therefore, the development of the biological synthesis of Ag NPs is advancing as a critical branch of nanotechnology. The use of biological entities, such as plant extracts, bacteria, actinomycetes, fungi or enzymes, for the generation of nanoparticles could be alternative to chemical and physical methods [94]. The advancements of biological synthesis of nanoparticles over chemical and physical methods are cost-effective and easily scaled up for vast-scale synthesis of nanoparticles, while high temperature and harmful solvents and reagents are not required for biological synthesis [95]. Compared with traditional chemical synthesis, the disadvantages are the limitation of reagents that makes it difficult to control the size and, more specially, the morphology of the nanoparticles, and the higher amounts of impurities compared with physical methods.

Biological synthesis using plants and plant extracts appears a relatively straightforward and advantageous approach compared with microorganisms, such as bacteria and fungi, due to its single-step technique, economical protocol and non-pathogenicity [94]. Plants have been extensively applied for the green synthesis of Ag NPs because plant extracts can act as both reducing and stabilizing agents, decreasing the cost and simplifying the process. Various plant resources, such as bark, roots, stems, fruits, seeds, callus, peels, 
leaves and flowers, have been explored by researchers till date to synthesize Ag NPs [95-97]. Additional steps such as extraction protocols or mixing extracts from different plants are also common in this type of synthesis.

Although the number of biological syntheses has grown rapidly in the last years, the synthesis protocols are still much less than in the case of chemical synthesis. Among the different examples, Anandan et al. [98], for instance, synthesized Ag NPs with distinct morphological characteristics using leaf exacts of Dodonaea viscosa as reducing agents. Five different polar and non-polar solvents (petroleum ether, methanol, acetone, acetonitrile and water) were used for the extraction of active ingredients from the leaves of Dodonaea viscosa, which attributed to obtaining nanoparticles with different properties. The high resolution-transmission electron microscopy (HR-TEM) analysis showed different nano sizes $(15,18,12$ and $20 \mathrm{~nm})$ of the nanoparticles with different surface morphologies (worm-like, irregular flower, spherical and dendritic structures) using methanol, acetone, acetonitrile and water extracts, respectively.

A cost-effective and straightforward biosynthesis of Ag NPs was reported by Hasnain et al. from the purple heart plant [99]. The aqueous methanolic extract was prepared and employed to synthesize Ag NPs by the biological reduction method using an aqueous solution of $\mathrm{AgNO}_{3}$. As described in their research, the effect of various independent factors (concentration of $\mathrm{AgNO}_{3}$, temperature, and the volume of leaves extract solution) on particle size, polydispersity index of synthesized Ag NPs was optimized using a Box-Behnken design. The synthesized Ag NPs at optimum condition are spherical with a particle size of $98 \mathrm{~nm}$, as observed by TEM.

Kalaiselvi et al. [100] revealed that the latex extract of Euphorbia tirucalli can produce Ag NPs against the root-knot nematode species, Meloidogyne incognita. The biosynthesized Ag NPs are spherical and cubic, with the particle size in the range of $20-30 \mathrm{~nm}$. Tripathi et al. [101] synthesized Ag NPs utilizing in vitro grown leaf extract of medicinal plant Withania coagulans by reducing $\mathrm{AgNO}_{3}$ solution. The results indicate that nanoparticles were spherical with an average size of $14 \mathrm{~nm}$ and had face-centered cubic (FCC) structure. In addition, prepared Ag NPs have antibacterial activity against both gram positive and negative bacteria. Ramesh et al. [102] reported that Ag NPs were synthesized using an aqueous leaf extract of Ficus hispida Linn. f. The formation rate of Ag NPs depended on the concentration of $\mathrm{AgNO}_{3}$, concentration of leaf extracts, temperature, $\mathrm{pH}$ and reaction time. The synthesized nanoparticles were spherical with an average particle size of $20 \mathrm{~nm}$. Other plants and plant extracts used for the synthesis of Ag NPs are given in Table 3.

Table 3. Biological synthesis of Ag NPs using plant and plant extracts.

\begin{tabular}{cccccc}
\hline Plants/Plants Extracts & Precursor & Reducing and Capping Agent & Size & Structure/Shape & Reference \\
\hline Rheum palmatum & $\mathrm{AgNO}_{3}$ & Root extract & $121 \pm 2 \mathrm{~nm}$ & $\begin{array}{c}\text { Hexagonal, } \\
\text { spherical, and } \\
\text { cubic }\end{array}$ & {$[103]$} \\
\hline Handelia trichophylla & $\mathrm{AgNO}_{3}$ & Shoot extract & $20-50 \mathrm{~nm}$ & FCC and spherical & {$[104]$} \\
\hline Turmeric powders & $\mathrm{AgNO}_{3}$ & Extract & $18 \pm 0.5 \mathrm{~nm}$ & Spherical & {$[105]$} \\
\hline $\begin{array}{c}\text { Bilberry and Red } \\
\text { Currant Waste }\end{array}$ & $\mathrm{AgNO}_{3}$ & Fruit extract & $25-65 \mathrm{~nm}$ & FCC & {$[106]$} \\
\hline Green tea extract & $\mathrm{AgNO}_{3}$ & Extract & $3.9 \pm 1.6 \mathrm{~nm}$ & FCC and spherical & {$[107]$} \\
\hline Reishi mushroom & $\mathrm{AgNO}_{3}$ & Extract & $15-22 \mathrm{~nm}$ & FCC and spherical & {$[108]$} \\
\hline Alternanthera dentata & $\mathrm{AgNO}_{3}$ & Leaf extract & $10-80 \mathrm{~nm}$ & FCC & {$[97]$} \\
\hline
\end{tabular}


Table 3. Cont.

\begin{tabular}{|c|c|c|c|c|c|}
\hline Plants/Plants Extracts & Precursor & Reducing and Capping Agent & Size & Structure/Shape & Reference \\
\hline $\begin{array}{l}\text { Plants from Myrtaceae } \\
\text { family }\end{array}$ & $\mathrm{AgNO}_{3}$ & Leaf extract & $5-55 \mathrm{~nm}$ & Spherical & [109] \\
\hline $\begin{array}{c}\text { Andrographis paniculata, } \\
\text { Phyllanthus niruri, } \\
\text { and Tinospora cordifolia }\end{array}$ & $\mathrm{AgNO}_{3}$ & $\begin{array}{l}\text { Stem and leaf } \\
\text { extract }\end{array}$ & $50-12 \mathrm{~nm}$ & Spherical & [110] \\
\hline $\begin{array}{l}\text { Stachytarpheta } \\
\text { cayennensis }\end{array}$ & $\mathrm{AgNO}_{3}$ & Leaf extract & $13 \mathrm{~nm}$ & FCC, and spherical & [111] \\
\hline $\begin{array}{c}\text { Memecylon umbellatum } \\
\text { Burm F }\end{array}$ & $\mathrm{AgNO}_{3}$ & Leaf extract & $7-23 \mathrm{~nm}$ & Spherical & [112] \\
\hline Galega officinalis & $\mathrm{AgNO}_{3}$ & Leaf extract & $8-34 \mathrm{~nm}$ & FCC and spherical & [113] \\
\hline Portulacaria afra & $\mathrm{AgNO}_{3}$ & Leaf extract & $27 \pm 4 \mathrm{~nm}$ & Irregular spherical & [114] \\
\hline Cleome viscosa L. & $\mathrm{AgNO}_{3}$ & Fruit extract & $20-50 \mathrm{~nm}$ & Spherical & [115] \\
\hline Origanum vulgare $\mathrm{L}$. & $\mathrm{AgNO}_{3}$ & Extract & $2-25 \mathrm{~nm}$ & FCC and spherical & [116] \\
\hline
\end{tabular}

\section{Silver Inks for Printing Techniques}

The typical inks used for printing methods contain functional particles (e.g., Ag NPs), binders, solvents, and additives. The common strategy for the formulation of silver inks is to add silver nanomaterials into polymers dissolved in suitable solvents to fabricate conductive inks. In some cases, this polymer could be the same as the capping agent that stabilizes the nanoparticles. In order to protect Ag NPs in inks against aggregation and oxidation, organic stabilizers/polymers are required. Then, a high-temperature sintering step is often needed to remove organic stabilizers and improve the conductivity, taking into account that the temperature may affect the substrate. More recently, a novel kind of metallic inks has been developed, called reactive ink, as a low-cost and promising alternative for fabricating highly conductive silver tracks. Reactive silver ink is a pure solution-phase ink mainly composed of a silver salt precursor and complexing agent. After printing, conductive silver can be generated through a reduction reaction and / or by the decomposition of a metal-organic precursor [28].

It should be noted that different performance and properties of conductive inks should be used by different printing technologies depending on the type of printing technology being used and the desired printed performance. In this review, three printing technologies (inkjet printing, screen printing and aerosol jet printing) are discussed. The inkjet printer ejects droplets of inks as required through the printing nozzle on a variety of substrates, as shown in Figure 5. There are two different modes of how the droplet is jetted from the nozzle, i.e., continuous inkjet printing and drop-on-demand printing. The optimum viscosity and surface tension for inkjet printing should be in the range $0.001-0.1 \mathrm{~Pa} \cdot \mathrm{s}$ and $15-25 \mathrm{mN} \cdot \mathrm{m}^{-1}$, respectively [28]. Screen printing is the process that transfers the inks pass through the patterned stencil with a squeegee, as shown in Figure 5. The optimum viscosity and surface tension for inkjet printing should be in the range $0.5-5 \mathrm{~Pa} \cdot \mathrm{s}$ and $0.001-0.1 \mathrm{~Pa} \cdot \mathrm{s}$ and $38-47 \mathrm{mN} \cdot \mathrm{m}^{-1}$, respectively [28]. Aerosol jet printing is the process that involves forming an ink aerosol and then spraying the aerosol onto the surface of the substrates, as shown in Figure 5. The aerosol jet printing technique permits working with a large range of viscosities (0.7-2500 $\mathrm{mPa} \cdot \mathrm{s})$ and lateral resolution even below $10 \mu \mathrm{m}$ [117]. 


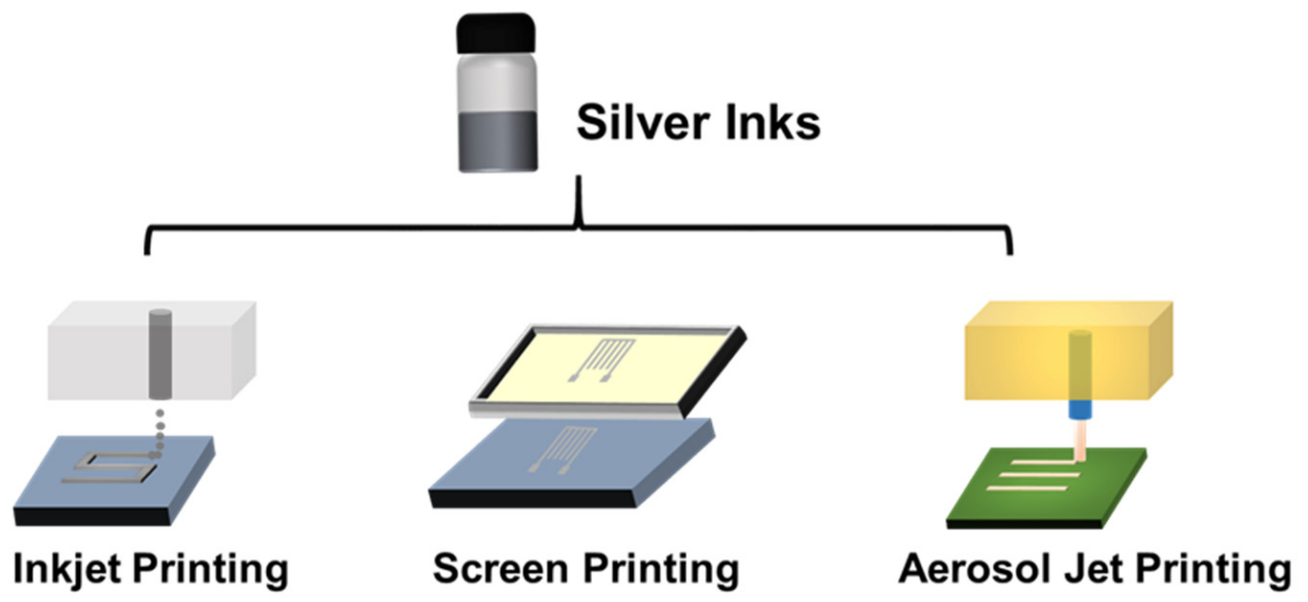

Figure 5. Schematic of inkjet printing, screen printing and aerosol jet printing.

Shen et al. [118] prepared highly stable dispersions of Ag NP inks and printed them on paper and polyethene terephthalate (PET) substrates using an inkjet printer. The low resistivity $(3.7 \mu \Omega \cdot \mathrm{cm})$ of the printed silver patterns can be achieved when the sintering temperature is $180^{\circ} \mathrm{C}$. Shahariar et al. [119] successfully produced particle-free silver ink by selecting a silver salt mixture with an amine solution, which can be converted into silver particles once heated to a temperature when a silver ion can be reduced. The conductive tracks are created by inkjet printing on uncoated polyester textile knit, woven, and nonwoven fabrics without changing the feel, texture, durability, and mechanical behavior of the material. However, the packing and tightness of fabric structures and fiber sizes of fabrics highly impact the conductivity and resolution of the printed tracks. Zope et al. [120] developed a solid silver complex for formulating silver ink by using silver oxalate as a precursor and ethylenediamine as a complexing agent. This solid silver complex provides longer shelf-life stability. In addition, a hybrid thermal-photonic curing approach was presented, which increased the electrical properties and substrate adhesion. The electrical resistivity of the printed silver traces is 2.7 times that of bulk silver.

Hyun et al. [121], for instance, used Ag NPs-based inks to print conductivity lines by screen printing where poly(acrylic acid) (PAA) acted as a capping agent and ethylene glycol as solvent. The synthesized silver ink was prepared with a high loaded concentration (77 wt.\%) what seemed suitable for screen printing and generated lines with the resistivity of $5.5 \times 10^{-6} \Omega \cdot \mathrm{cm}$. Wang et al. [122] synthesized Ag NP inks in an aqueous solution and printed the inks on cotton fabric using screen printing. Low resistivity $\left(2 \times 10^{-5} \Omega \cdot \mathrm{m}\right)$ was achieved with $30 \mathrm{wt} . \%$ of silver content. Kell et al. [123] developed a screen-printable ink containing metal carboxylate salt as a silver metal precursor and a polymer binder as the carrier. That screen-printed traces with good electrical $(12 \mu \Omega \cdot \mathrm{cm})$ and mechanical properties were achieved using thermal or photonic sintering. The addition of ethyl cellulose to silver precursor formulation increases the viscosity of ink to enable screen printing, lowers the decomposition temperature of the silver neodecanoate salt, and improves trace adhesion to the plastic substrate, leading to robust mechanical properties.

Apart from the requirements regarding the Ag NPs or the silver precursors, the different types of inks should be adequate for the processing type. From those, inkjet, screen, and aerosol jet printings are the more relevant and are discussed below, as shown in Figure 5.

\subsection{Formulation of Silver Inks for Inkjet Printing}

Typically, the inks for inkjet printing require a viscosity in the range from 0.001 to $0.1 \mathrm{~Pa} \cdot \mathrm{s}$ and surface tension from 15 to $25 \mathrm{mN} \cdot \mathrm{m}^{-1}$ [28]. Therefore, during and after the Ag NPs synthesis must be taken care of fitting these recommended ranges. That is usually assured by controlling Ag NPs concentration, using a suitable solvent or additives. Cheon 
et al. [124] reported on the synthesis of Ag NPs for inkjet printing using electrolysis. The authors showed that they could obtain Ag NPs of different sizes (10-80 nm) by controlling the applied voltage and the electrolyte temperature. The used electrolyte consisted of citric acid, hydrazine monohydrate, dispersion agent in deionized water. Kosmala et al. [125] reported on the synthesis of aqueous Ag NPs inks by a simple wet chemistry method, resulting in the formation of Ag NPs with a diameter around $50 \mathrm{~nm}$. The authors used a triblock copolymer as Ag NPs dispersing agent and a high-intensity focus ultrasound to reduce the particle size from $\sim 200 \mathrm{~nm}$ to $50 \mathrm{~nm}$. Chen et al. [126] used a one-step synthesis of Ag NPs in a toluene solution containing dodecanoic acid or octadecanoic acid with the addition of n-butylamine and hydrazine, as shown in Figure 6. The Ag-dodecanoic acid NPs were finally suspended at $10 \mathrm{wt}$ \% in cyclohexane to be employed in inkjet printing.

(a) Ag NPs synthesis

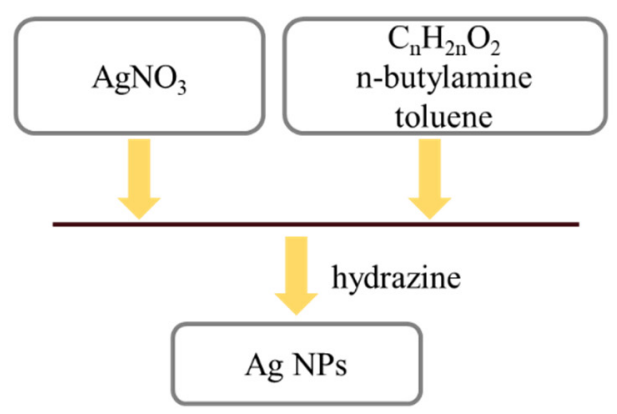

(b) Room-Temperature Direct-Printing Process

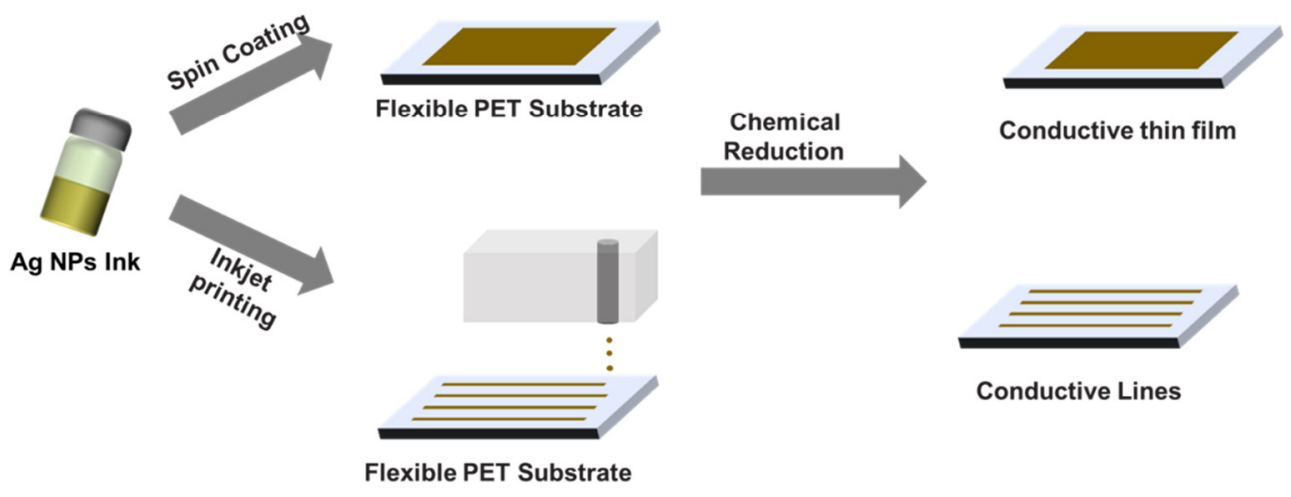

Figure 6. (a) Schematic illustration of the whole process of Ag NPs synthesis; and (b) the direct printing process.

Jung et al. [127] showed a simple way of synthesizing and sintering Ag NPs employing a simple thermal decomposition process. The Ag NPs were synthesized by simple heating and stirring of $\mathrm{AgNO}_{3}$ in the presence of the surfactant (oleylamine), without a reducing agent. After dispersion and centrifugation in toluene and methanol, Ag NPs were dispersed in hexadecane at the concentration of $30 \mathrm{wt}$ \%. Tung et al. [128] synthesized Ag NPs with different shapes (spherical, prism, rod, and multifaceted NPs) by variation of PVP concentration using a rapid water radiolysis approach via $X$-ray diffraction analysis (XRD). The resulting NPs aspect ratio from 1 up to $\sim 50$ was reached for optimized reagent concentrations. The ink concentration for inkjet printing was set to $15 \mathrm{wt} \%$ in methanol. Novara et al. [129] used "in situ" reduction of silver by printing $\mathrm{AgNO}_{3}$ solutions on the porous silicon surface covered with reactive hydrides. The authors also investigated the influence of $\mathrm{AgNO}_{3}$ concentration and solvents (water-ethanol, water-dimethyl sulphoxide) on the morphology of the printed Ag NPs layer. Zhang et al. [130] used a tannic acid (TA) to 
stabilize the synthesized Ag NPs, which resulted in an environmentally friendly approach to upscale the inkjet printable Ag NPs based inks. The Ag NPs were prepared by the employment of the silver ammonia as a silver source and TA as a reducing and capping agent simultaneously. The whole reaction was carried out in a deionized water medium at room temperature for a very short time $(30 \mathrm{~min})$. The formation of Ag NPs was observed by the color changes of the solution color from colorless to yellowish and finally dark brown. Subsequently, the Ag NPs with an average diameter of $15 \mathrm{~nm}$ were purified in ethanol and deionized water, and collected by precipitation and drying. The obtained Ag NPs could be stored without oxidation for several months. Ag NPs inks at the solid content of 1-10 wt.\% were prepared by dispersing different quantities of Ag NPs in deionized water. In addition, $25 \mathrm{vol} . \%$ of isopropanol was used to adjust the surface tension and viscosity of the ink. Conductive patterns were obtained by inkjet printing the Ag NPs inks onto photo paper. Low resistivity was achieved with sintering at $200{ }^{\circ} \mathrm{C}$.

Liu et al. [131] showed how to synthesize bimodal Ag NPs by changing the solution temperature and concentration of $\mathrm{AgNO}_{3}$. The authors first synthesized $\mathrm{Ag}$ NPs of $10 \mathrm{~nm}$ in size at room temperature and $\mathrm{AgNO}_{3}$ concentration of $100 \mathrm{~g} \cdot \mathrm{L}^{-1}$, and subsequently, larger $\mathrm{Ag}$ NPs of $50 \mathrm{~nm}$ at a boiled state and $\mathrm{AgNO}_{3}$ concentration of $0.54 \mathrm{~g} \cdot \mathrm{L}^{-1}$. Finally, the prepared Ag NPs of the two different sizes were mixed in different ratios. The ratio of 2:1 (Ag NPs of $10 \mathrm{~nm}$ in size and Ag NPs of $50 \mathrm{~nm}$ in size) resulted in a decreased resistivity of $3.66 \times 10^{-6} \Omega \cdot \mathrm{cm}$, with respect to each of them individually. Furthermore, the improved mechanical stability of the printed layers was also observed for this ratio.

Barrera et al. [132] synthesized Ag NPs by employing two different methods (chemical and microwave radiation). The chemical method was based on adding $\mathrm{AgNO}_{3}$ into a solution of $\mathrm{NaBH}_{4}$ and subsequently adding sodium citrate and PVP to stabilize the solution. The synthesis by microwave radiation was realized by mixing $\mathrm{DMF}, \mathrm{AgNO}_{3}$, and PVP in the tube of a single-mode reactor microwave under constant magnetic agitation. The Ag NPs prepared by microwave radiation were mixed with polyvinyl butyral (PVB), resulting in a nanocomposite with improved antibacterial properties with respect to Ag NPs prepared by chemical method.

Trinh et al. [133] prepared Ag NPs by chemical reduction of $\mathrm{AgNO}_{3}$ using $\mathrm{NaBH}_{4}$ with chitosan (CS) and cetyltrimethylammonium bromide (CTAB) as capping agents. The synthesized Ag NPs improved ink stability (more than 6 months) and cubic crystal structure with a size under $10 \mathrm{~nm}$. After the synthesis, Ag NPs were mixed with glycerol, isopropanol, and deionized water to achieve the ink with appropriate viscosity and surface tension.

Another synthesis approach was used by Hao et al. [134], who applied a carboxylterminated hyperbranched polymer (CHBP) to stabilize the synthesized Ag NPs according to the procedure shown in Figure 7. The Ag NPs with almost monodisperse particles and a diameter of 10-20 nm were synthesized by chemical reduction of $\mathrm{AgNO}_{3}$ using $\mathrm{NaBH}_{4}$ in an aqueous phase. The final resistivity of the printed Ag NPs layers sintered at $180{ }^{\circ} \mathrm{C}$ was $10.83 \mu \Omega \cdot \mathrm{cm}$, which is approximately seven times higher than in case of bulk silver $(1.58 \mu \Omega \cdot \mathrm{cm})$.

Yang et al. [135] showed a simple way to prepare Ag particle-free inks, which could be a possible cheap substitute for Ag NPs based inks, as shown in Figure 8. The ink was prepared by simple dissolution of a silver oxalate powder in different alcohols (methanol, ethanol, butanol, hexanol and 2-methoxyethanol or a mixture of them) using 1,2-diaminopropane $(1,2-\mathrm{DAP})$ as the ligand. After the printing and sintering at $180^{\circ} \mathrm{C}$, the resulting silver layer resistivity was $15.46 \mu \Omega \cdot \mathrm{cm}$, which is only ten times higher than that of bulk silver. 


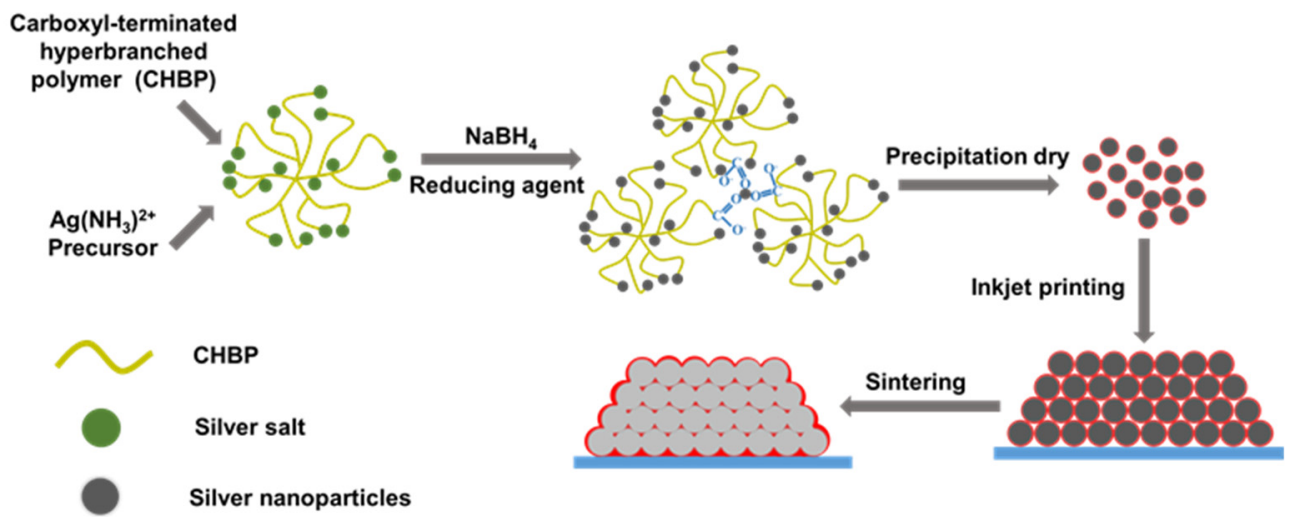

Figure 7. Schematic illustration of the CHPB stabilized Ag NPs and the process Ag NPs sintering.

(a)

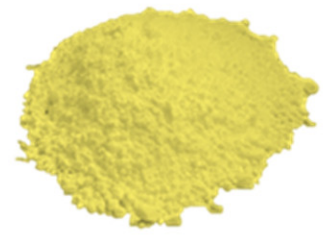

Silver oxalate

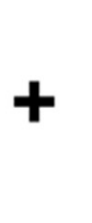

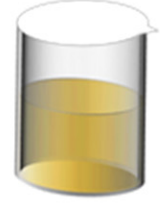

Alcohol

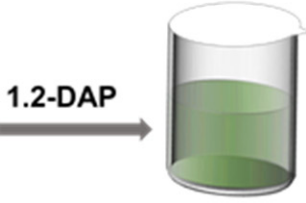

Ink

(b)<smiles>O=C(O[Ga])C(=O)O[Ge]</smiles><smiles>CC(N)CN</smiles>

Figure 8. (a) Schematic illustration of the one-pot silver particle-free ink and (b) chemical reaction occurring during the ink synthesis.

\subsection{Formulation of Silver Inks for Screen Printing}

The screen printing technique typically works with viscosities ranging from 0.5 to $5 \mathrm{~Pa} \cdot \mathrm{s}$ and the surface tension from 38 to $47 \mathrm{mN} \cdot \mathrm{m}^{-1}$ [28]. Therefore, to comply with such requirements, Ag NPs need to be dispersed in a suitable polymer matrix and solvent, which assure the sufficiently high viscosity of the ink. Jadav et al. [136] used the bottom-up technique to synthesize Ag NPs, which were subsequently used to formulate a silver/silver chloride $(\mathrm{Ag} / \mathrm{AgCl})$ screen-printable ink for fabrication of electrodes for detection of vitamin $C$ concentration from fruit juices. The authors used epoxy resin as a binder combined with a commercial hardener to achieve the desirable rheologic characteristics that made it suitable for the screen printing process. In another work of Liu et al. [137], the authors used an anion-mediated synthesis to prepare monodisperse Ag NPs. They used $\mathrm{AgNO}_{3}$ as a metal source, in combination with glucose, $\mathrm{PVP}$, and different anions $\left(-\mathrm{SO}_{4}{ }^{2-},-\mathrm{PO}_{4}{ }^{3-},-\mathrm{CO}_{3}{ }^{2-}\right.$ and $\left.-\mathrm{Br}^{-}\right)$to tailor the morphology of the particles. The authors also investigated the influence of the nitrate-glucose ratio and reaction temperature on the shape and size of the synthesized Ag NPs. These nanoparticles were then re-dispersed in ethanol at a concentration of $30 \mathrm{wt} . \%$, subsequently screen-printed onto the PET and paper substrate, and sintered at room temperature. Ding et al. [138] used a one-step polyol method to upscale the Ag NPs synthesis in ethylene glycol in the presence of PVP. The particle size (from 52 to $120 \mathrm{~nm}$ ) was controlled by the mass ratio variation of $\mathrm{AgNO}_{3}$ and PVP. Subsequently, the Ag NPs were re-dispersed in ethanol at $70 \mathrm{wt} . \%$ and printed 
in different conductive structures on PET substrate, reaching conductivities close to bulk silver, as shown in Figure 9.

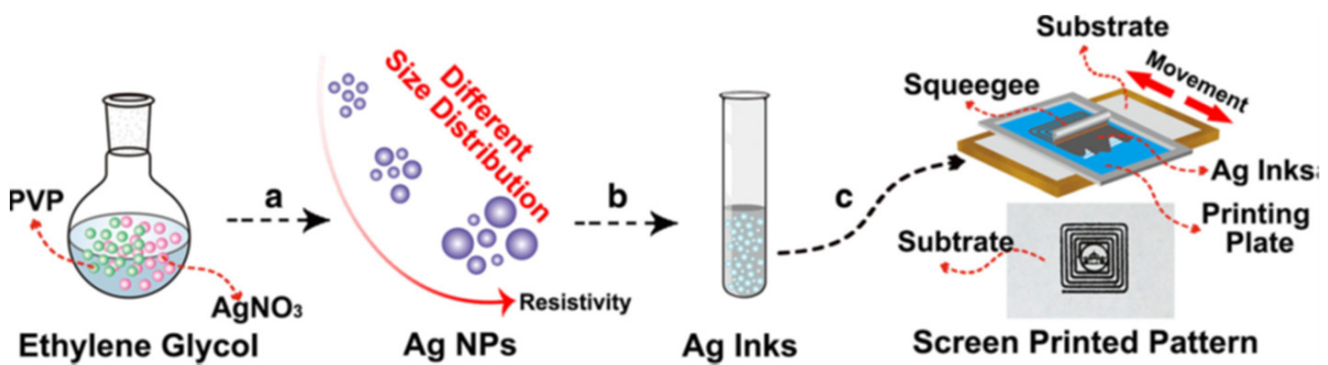

Figure 9. Schematic illustration of the whole process of screen printing Ag NP-based ink preparation from the synthesis to the printing of conductive pattern. (a) The preparation of Ag NPs with different size distribution; (b) The dispersion of Ag NPs in ethanol to form silver inks; (c) Screen printing of silver inks. Reprinted from Ref. [138].

\subsection{Formulation of Silver Inks for Aerosol Jet Printing}

The aerosol jet printing technique permits working with a large range of viscosities (0.7-2500 $\mathrm{mPa} \cdot \mathrm{s})$ and lateral resolution even below $10 \mu \mathrm{m}$ [117]. Salary et al. [117] also point out that aerosol jet printing is very sensitive to ink temperature and solvent evaporation rate, which may cause instabilities during the printing, such as pre-drying or particle accumulation within the printer nozzle.

Shankar et al. [139] used the non-aqueous synthesis in toluene with dodecylamine, and subsequent addition of silver acetate and a small amount of tin acetate, resulting in a formation of Ag NPs of 5-20 nm in size. The synthesized Ag NPs were then dispersed in decane and the viscosity (1-2 $\mathrm{mPa} \cdot \mathrm{s})$ of the solution was adjusted by adding 2-buthoxyethanol at the concentration of $20 \%$ by weight. Ivanov et al. [140] used a pulsed-periodic gas discharge in an air atmosphere to produce Ag NPs with a multigap gas-discharge generator from $99.95 \%$ purity silver. The resulting Ag NPs were then deposited by a focused aerosol beam on a glass substrate. Sonawane et al. [141] deposited branched polyethylenimine (BPEI)-functionalized Ag NPs on a substrate utilizing aerosol with flowing argon gas. BPEI-functionalized Ag NPs were dispersed at a concentration of $0.02 \mathrm{mg} / \mathrm{mL}$ in deionized water. To create the aerosol, the solution was poured into an ultrasonic nebulizer with an additional inlet for argon gas and an outlet connected to a quartz tube, followed by the plasma treatment. After the plasma treatment, the size of the Ag NPs was reduced from 10 to $5 \mathrm{~nm}$, and a well-dispersed film was formed. The plasma treatment resulted in morphological changes in Ag NPs, enhancing their optical properties. Additionally, the plasma treatment resulted in a blue shift of approximately $70 \mathrm{~nm}$ in the peak of the surface plasmon resonance, which is typical for the high-temperature thermal treatment. Therefore, no additional thermal sintering was necessary in this case. The desired deposition and plasma treatment can be applied to a wide range of nanoparticle systems on flexible substrates.

\section{Post-Printing Treatments}

In order to form effective conductive paths, sintering processes are commonly necessary after the deposition of conductive silver inks, especially in metal-based nanoparticles inks. Generally, Ag NPs are dispersed in an aqueous/organic solution capped with organic stabilizers that act as an insulator, affecting the conductivity of printed tracks. Sintering removes the organic components by heating to the desired temperature, as shown in Figure 10. The sintering treatment induces the removal of stabilizers and coalescence of solid nanoparticles, and the sintering temperature is mainly dependent on the type of stabilizers to remove [142]. For reactive Ag inks, in addition to the organic solvent evaporation, the sintering process triggers chemical reactions in the ink to produce conductive silver patterns. Understanding the correlation between sintering temperature, sintering 
process type and time and the morphology of nanomaterials, and the electrical properties of printed patterns is important to predict and improve the performance of the ink. There are many sintering methods, such as conventional thermal sintering, chemical sintering, electrical sintering, photonic sintering, and plasma sintering.

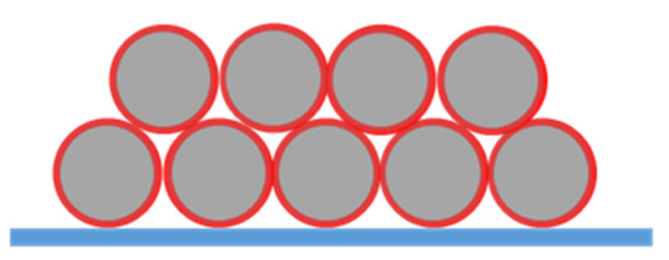

After printing
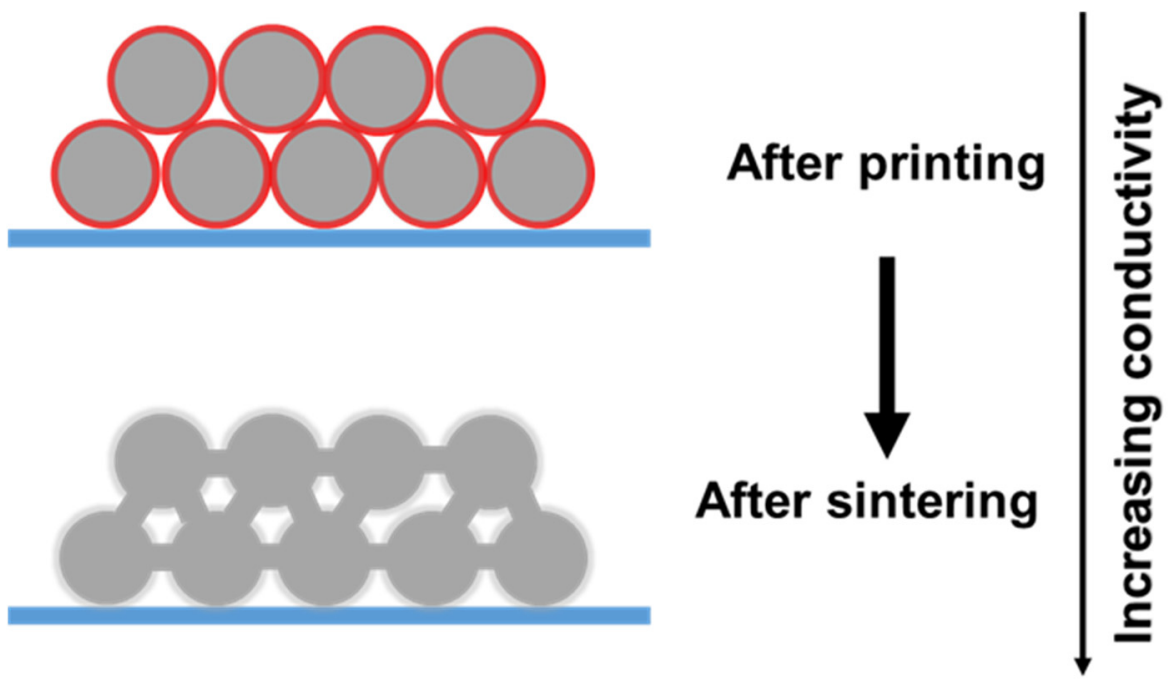

Figure 10. Schematic illustration of the sintering treatment process.

\subsection{Thermal Sintering Method}

Thermal sintering is the most straightforward method as the temperature removes the stabilizers either by evaporation or decomposition. For reactive silver inks, the sintering temperature triggers the chemical reaction of the silver precursor. Therefore, the thermal sintering highly depends on the size of silver particles, the volatilization or decomposition temperature of organic compositions in the inks, and the boiling of the solvent [143].

The effects of sintering temperature and time on microstructure and electrical properties of silver ink films have been investigated by Yang et al. [144]. Sintering at higher temperatures leads to a larger particle size of silver nanocrystals in printed film. The morphology of the films changes with the sintering temperature, resulting from the fast evaporation of the solvent and thermal decomposition and reduction of the complex. Moreover, with increasing time, the printed films show relatively more compact microstructures consisting of small silver particles with better film uniformity.

The high disadvantage of this method is that the temperature required for thermal sintering is not easy to implement on many substrates, such as plastic, paper, or elastomers. Hence, the development of low-temperature sintering technologies is particularly relevant in this field.

\subsection{Chemical Sintering Method}

Chemical sintering can be carried out at room temperature by adding chemical reagents, which can cause destabilization of the metal particle/stabilizer system and allow direct contact of the metal nanoparticles to form conductive paths. Among chemical sintering, two possible methodologies, i.e., dissolving or detachment of the protective layers on surfaces of nanoparticles, can be applied [28,142,145,146].

As a dissolving method, Wakuda et al. [147,148] studied the extraction of the dodecylamine stabilizing molecules from nanoparticles by dipping printed lines in several alcohols (ethanol, methanol, isopropanol). Dodecylamine has excellent solubility in alcohols, which can remove the weak bonds between Ag NPs and dodecylamine, causing coalescence and sintering of Ag NPs. An example of a detachment method is the one presented by Grouchko et al. [149], where chloride caused room temperature sintering of Ag NPs stabilized by polyacrylic acid sodium salt. As illustrated in Figure 11, due to the presence of 
the destabilizing agent, the desorption of the stabilizing polymer from the surface of the nanoparticles occurs, causing coalescence and sintering of Ag NPs. In that study, about $41 \%$ of the conductivity of bulk silver could be reached by using hydrochloric acid $(\mathrm{HCl})$ vapors as a sintering agent. This method makes the possibility to print on heat-sensitive materials.

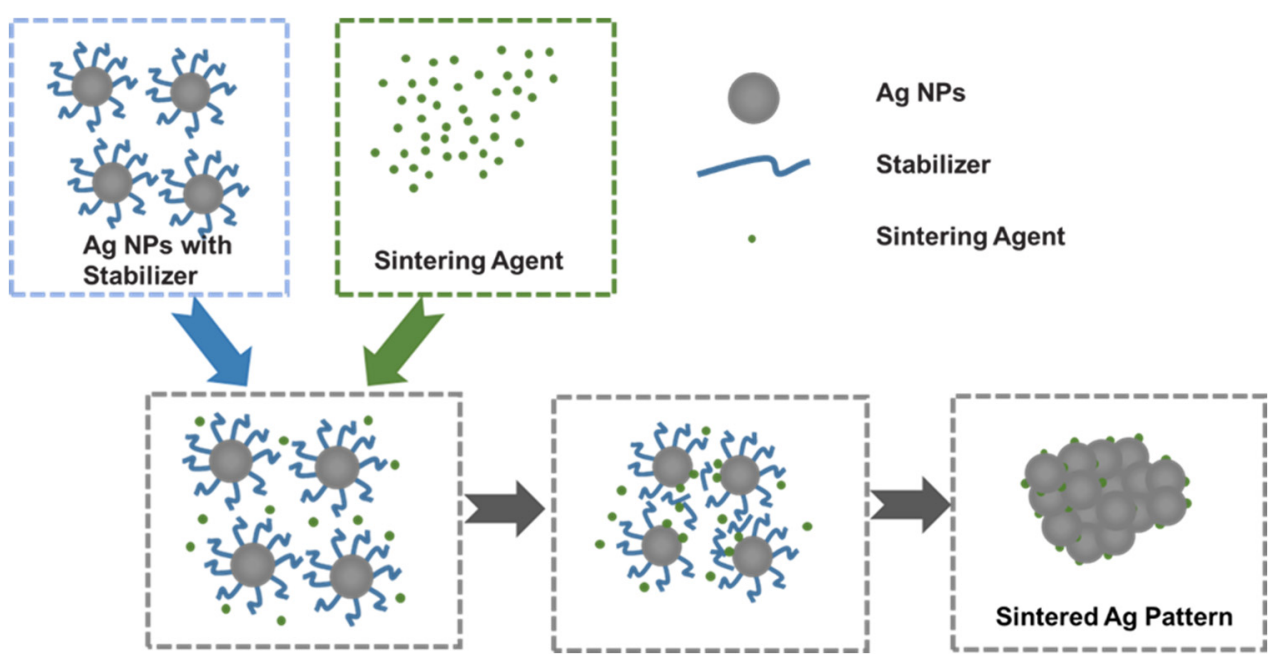

Figure 11. Schematic illustration of chemical sintering of nanoparticles due to the detachment of stabilizers.

\subsection{Electrical Sintering Method}

Electrical sintering consists of applying a current across the printed pattern resulting in local heating due to the highly resistive nature of silver ink before sintering $[142,143,150]$, as shown in Figure 12. Consequently, electrical sintering is a local Joule heating sintering method, which minimizes the thermal damage to the substrate [151]. Electrical sintering can tailor the degree of sintering by controlling the heating current. Hummelgård et al. [152] investigated the entire sintering process in real-time using an in situ TEM. The onset of sintering and coalescence of nanoparticles starts at power levels of $0.1-10 \mathrm{~mW} / \mu \mathrm{m}^{3}$. In addition, when the ink was Joule-heated, the first cause of conductivity increase was the carbonization of the solvent. Instead of burning off the solvent, carbonization helps prevent micro-cracking of the sintered structure.

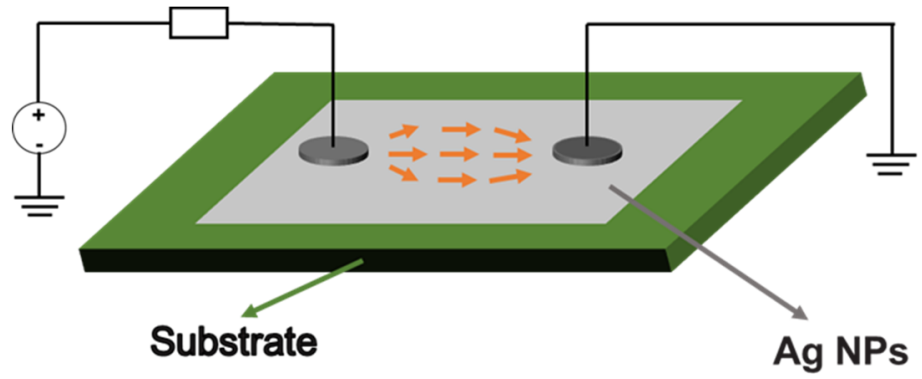

Figure 12. Schematic illustration of an electrical sintering setup.

The temperature affects the specific resistance of printed patterns during the electrical sintering process. Moon et al. [153] studied the relationship between the specific resistance of the ink and the sintering temperature using the Wiedemann-Franz law showing that the resistance of the ink decreases as the process temperature rises. However, thermal damage can result from the high initial resistance of printed patterns. Stepwise current electrical sintering was devised by Lee et al. [154]. By increasing the current gradually, the conductive line can endure a higher current since the specific resistance has progressively dropped during the process. Compared with the constant current-supplying electrical sintering 
method, the enhanced final-step current produces lower resistance of the conductive line without damaging printed patterns.

\subsection{Photonic Sintering Method}

The sintering of printed metal patterns by electromagnetic irradiation ranging between the ultra-violet (UV) and infrared (IR) is called photonic sintering [155]. Metal nanoparticles on common substrates such as polymer foils or glass show very intense absorption in the visible region due to their plasmonic properties. There is a significant difference in the optical properties between the metal nanoparticles to be sintered and common substrates. Glass and other common polymer substrates have absorption only in the UV range, except PI because of its brown color. Under an appropriated emission spectrum and sufficient optical power density, photonic sintering exploits the possibility of heating the printed ink by photothermal effects, leaving the transparent substrate material unaffected $[8,142]$. Photonic sintering includes laser sintering, IR sintering, and intense pulsed light (IPL) or photonic flash sintering.

The laser sintering is performed using a high-power laser as the power source to melt and fuse the powders into solid structures. The energy provided by laser is absorbed by printed tracks in a selected area controlled by a computer system, resulting in decomposition of organic components in the inks and rapid sintering. The nanoparticle inks heat up due to the photothermal effect and then are sintered due to the locally elevated temperature. After laser sintering, the parts with desired electricity and functionality can be obtained [143]. The generated temperature inside the ink has to be controlled and kept as low as possible to avoid the dissipated heat from the ink to the substrate, which can be realized by tuning the pulse length, flashing frequency, sintering time, and intensity of the lamp. Hong et al. [156] developed a method to fabricate a metallic grid transparent conductor on a plastic substrate using selective laser sintering of metal nanoparticles. The fine grid conductor yields a high transmittance $(>85 \%)$ and low sheet resistance $(<30 \Omega / \mathrm{sq})$, which can be directly applied to a large-area flexible substrate. Theodorakos et al. [157] compared three different laser sources with different pulse duration (continuous wave, pulsed nanosecond and picosecond) at 532 and $1064 \mathrm{~nm}$ to sinter Ag NP inks. It was found that continuous wave and nanosecond-pulsed laser sintered the NPs inks efficiently but may damage the substrate depending on the laser power and the spatial laser intensity profile. Alshammari et al. [158] found a strong dependence of the morphology and electrical performance of the printed samples on the process parameters, namely the laser fluence and the scanning speed of the laser. The received conductivity values with optimal laser condition at a scan speed of $5 \mathrm{~mm} / \mathrm{s}$ and beam energy of $30 \mathrm{~mJ} / \mathrm{cm}^{2}$ are comparable to that obtained for the thermally sintered ones, which is about one order of magnitudes less than that of bulk silver. The printed conductive patterns were then successfully utilized as electrodes for organic thin-film transistors.

IR technology uses irradiation in the range of NIR to MIR region (700 to 15,000 nm) to dry and sinter printed inks within a short time. Moreover, Sowade et al. [159] reported roll-to-roll (R2R) IR drying and sintering of printed Ag patterns on flexible polymer substrates with high web velocities (up to $1 \mathrm{~m} \cdot \mathrm{s}^{-1}$ ) within one second. The obtained results contributed to the development of IR system to sinter materials for R2R-printed electronics. The IR conditions, including the power of the IR lamp, the distance between the IR lamp and substrate, and the sintering time, should be tuned appropriately to avoid the damage of the flexible substrate and printed patterns. Park et al. [160] performed IR sintering in a large-area R2R gravure printing process for printed Ag NPs and Ag flake layers. Relevant process conditions, e.g., IR lamp power, distance from the IR lamp to printed patterns, and exposure time, were varied to evaluate the effects on the sheet resistance of the two types of pastes. They found that the distance between the substrate and IR lamp is the most influential parameter in all the samples, whereas the second most effective parameter is the sintering time. The lamp power is insignificant in the Ag NP pattern, but it is significant in the Ag flake layer. 
IPL employs a Xenon flash lamp with a wide wavelength ranging from hundreds to thousands of $\mathrm{nm}$ to generate heat in the target materials to achieve the necessary temperature increase, as shown in Figure 13. However, high-intensity light onto the front surface of metal nanoparticle patterns often causes the defects, such as delamination, cavities, and cracks in the patterns. Kwak et al. [161] presented a back-irradiation method for obtaining defect-free high conductivity Ag NP patterns in a few milliseconds, wherein the back surface of the patterns is irradiated with IPL through a transparent plastic substrate. In contrast to the back-irradiated patterns, the vapor is trapped in the front-irradiated patterns. It delaminates the patterns from the substrate because the front of the patterns acts as a barrier to vapor venting.

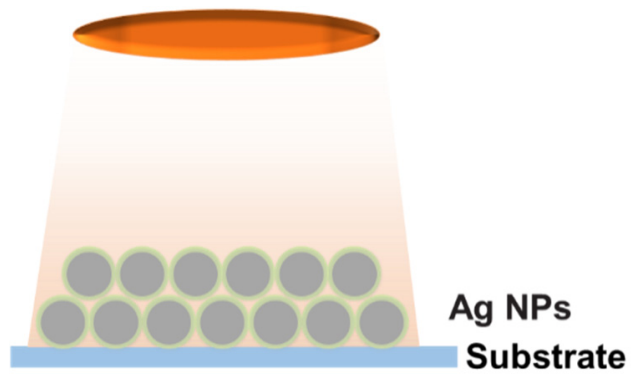

Figure 13. Scheme of the IPL sintering setup. A Xenon flash lamp with a wide wavelength is used to generate heat in the target materials.

\subsection{Plasma Sintering Method}

In general, plasma sintering is performed by exposure of printed patterns to lowpressure argon plasma. During plasma generation, the plasma produces excited species, such as ions, radicals, and UV irradiation, causing decomposition of the stabilizing agent and enabling direct contact between metal particles [162]. The plasma sintering process starts from the top to the bottom in the structure, and sintering does not occur with greater thickness than the penetration depth of the plasma species [163]. High conductivity values of up to $60 \%$ of bulk silver were obtained by Perelaer et al. at a temperature compatible with the glass transition temperature of common polymer foils using two sequential sintering techniques, low-pressure argon plasma sintering and microwave flash sintering [164]. Instead of low-pressure plasma sintering, Wünscher et al. [165] combined atmospheric pressure plasma sintering and a mild thermal treatment to reduce the sintering time and improve the conductivity of inkjet-printed Ag NP inks. Temperature-assisted atmospheric pressure plasma sintering revealed a conductivity of $16 \%$ of the bulk silver and reduced the process time by a factor of five compared to low-pressure plasma sintering as well as conventional thermal sintering. Ma et al. [166] sintered Ag NP inks on glass substrates using argon plasma and studied the effects of plasma parameters on the electrical property, material composition, and film nanostructure of sintered Ag NPs films. The lowest resistivity of the sintered layer was five times higher than that of bulk silver.

\section{Outlooks and Perspectives}

Ag NPs have attracted considerable attention due to their high electric conductivity, good oxidation resistance, optical characteristics, and antibacterial effects. As follows from the above overview, many kinds of nanoparticles can be synthesized, which could be utilized in electronic, optoelectronic, and biological fields. Ag-based inks can be printed on various substrates to obtain conductive patterns. The strategies of achieving highly conductive Ag NPs-based designs by moderate sintering have been given in this review. A better understanding of the relationship among the sintering condition, the protective agents, Ag NPs size, and shapes has been covered. The development of fast, efficient, and inexpensive sintering methods is also highlighted. 
Although remarkable scientific progress in the preparation of nanoparticles and sintering of conductive patterns has been achieved, there are still challenges that call for further development in order to be implemented by the industry at a large scale. The current high price of commercial Ag NPs is one of the critical factors. The development of new Ag NPs deserves more attention, which could decrease the ink dosage and printed ink thickness and increase the electric conductivity. In addition, selecting a suitable sintering method for the printing patterns is crucial to obtain good conductive printed patterns. An unsuitable sintering method could cause higher resistance and porosity after the metal ink is sintered. Since the temperature-sensitive substrates (flexible plastic and paper) require low-temperature sintering, further development of new sintering techniques, which are compatible with $\mathrm{R} 2 \mathrm{R}$ printing processes, is crucial to their industry applications.

Author Contributions: J.Z.: investigation, formal analysis, writing-review, and editing; M.A.: formal analysis, and methodology; N.P., J.R. and S.L.-M.: funding acquisition, writing-review, and editing; L.L.: funding acquisition; G.F. and E.J.-P.: conceptualization, formal analysis, resources, supervision, validation, funding acquisition, project administration, and writing — review, and editing. All authors have read and agreed to the published version of the manuscript.

Funding: This work has been partially funded by the EU Regional Development within the framework of the Operational FEDER of Catalonia 2014-2020 RIS3CAT-BASE3D. The research leading to these results has received funding from the European project AMITIE (Marie Skłodowska Curie Grant Agreement no. 734342). This work has been supported by Grants no. PGC2018-096855-B-C41 and PID2019-106631GB-C41 from Spanish Ministry of Science, Innovation and Universities. This work has been partially funded by the Basque Government Industry and Education Department under the ELKARTEK and PIBA (PI-BA-2018-06) programs, respectively, by the European Union's Horizon 2020 Programme for Research, ICT-02-2018-Flexible and Wearable Electronics, Grant agreement no. 824339-WEARPLEX.

Institutional Review Board Statement: Not applicable.

Informed Consent Statement: Not applicable.

Data Availability Statement: Not applicable.

Acknowledgments: This work has been partially funded by the EU Regional Development within the framework of the Operational FEDER of Catalonia 2014-2020 RIS3CAT-BASE3D. The research leading to these results has received funding from the European project AMITIE (Marie Skłodowska Curie Grant Agreement no. 734342). We acknowledge the funding from Spanish Ministry of Science, Innovation and Universities by Grants no. PGC2018-096855-B-C41 and PID2019-106631GB-C41. The authors thank funding from the Basque Government Industry and Education Department under the ELKARTEK and PIBA (PIBA-2018-06) programs, respectively. We acknowledge funding from the European Union's Horizon 2020 Programme for Research, ICT-02-2018-Flexible and Wearable Electronics, Grant agreement no. 824339-WEARPLEX. J. Zhang was supported by a China Scholarship Council (CSC) scholarship (no. 201706740094).

Conflicts of Interest: The authors declare no conflict of interest.

\section{References}

1. Abbasi, E.; Milani, M.; Aval, S.F.; Kouhi, M.; Akbarzadeh, A.; Nasrabadi, H.T.; Nikasa, P.; Joo, S.W.; Hanifehpour, Y.; Nejati-Koshki, K.; et al. Silver Nanoparticles: Synthesis Methods, Bio-Applications and Properties. Crit. Rev. Microbiol. 2016, 42, 173-180. [CrossRef] [PubMed]

2. Nair, L.S.; Laurencin, C.T. Silver Nanoparticles: Synthesis and Therapeutic Applications. J. Biomed. Nanotechnol. $2007,3,301-316$. [CrossRef]

3. Salomoni, R.; Léo, P.; Montemor, A.F.; Rinaldi, B.G.; Rodrigues, M.F.A. Antibacterial Effect of Silver Nanoparticles in Pseudomonas Aeruginosa. Nanotechnol. Sci. Appl. 2017, 10, 115-121. [CrossRef] [PubMed]

4. Pajor-Świerzy, A.; Farraj, Y.; Kamyshny, A.; Magdassi, S. Air Stable Copper-Silver Core-Shell Submicron Particles: Synthesis and Conductive ink Formulation. Colloids Surf. A Physicochem. Eng. Asp. 2017, 521, 272-280. [CrossRef]

5. Yaqoob, A.A.; Umar, K.; Ibrahim, M.N.M. Silver Nanoparticles: Various Methods of Synthesis, Size Affecting Factors and Their Potential Applications-A Review. Appl. Nanosci. 2020, 10, 1369-1378. [CrossRef] 
6. Agarwala, S.; Lee, J.M.; Yeong, W.Y.; Layani, M.; Magdassi, S. 3D Printed Bioelectronic Platform with Embedded Electronics. MRS Adv. 2018, 3, 3011-3017. [CrossRef]

7. Zhou, X.; Parida, K.; Halevi, O.; Liu, Y.; Xiong, J.; Magdassi, S.; Lee, P.S. All 3D-Printed Stretchable Piezoelectric Nanogenerator with Non-Protruding Kirigami Structure. Nano Energy 2020, 72, 104676. [CrossRef]

8. Kamyshny, A.; Magdassi, S. Conductive Nanomaterials for 2D and 3D Printed Flexible Electronics. Chem. Soc. Rev. 2019, 48, 1712-1740. [CrossRef]

9. Huang, Q.; Zhu, Y. Printing Conductive Nanomaterials for Flexible and Stretchable Electronics: A Review of Materials, Processes, and Applications. Adv. Mater. Technol. 2019, 4, 1800546. [CrossRef]

10. Wu, Q.; Zou, S.; Gosselin, F.P.; Therriault, D.; Heuzey, M.C. 3D Printing of a Self-Healing Nanocomposite for Stretchable Sensors. J. Mater. Chem. C 2018, 6, 12180-12186. [CrossRef]

11. Yin, X.Y.; Zhang, Y.; Cai, X.; Guo, Q.; Yang, J.; Wang, Z.L. 3D Printing of Ionic Conductors for High-Sensitivity Wearable Sensors Mater. Horiz. 2019, 6, 767-780. [CrossRef]

12. Shi, L.; Layani, M.; Cai, X.; Zhao, H.; Magdassi, S.; Lan, M. An Inkjet Printed Ag Electrode Fabricated on Plastic Substrate with a Chemical Sintering Approach for the Electrochemical Sensing of Hydrogen Peroxide. Sens. Actuators B Chem. 2018, 256, 938-945. [CrossRef]

13. Peng, X.; Yuan, J.; Shen, S.; Gao, M.; Chesman, A.; Yin, H.; Cheng, J.; Zhang, Q.; Angmo, D. Perovskite and Organic Solar Cells Fabricated by Inkjet Printing: Progress and Prospects. Adv. Funct. Mater. 2017, 27, 1703704. [CrossRef]

14. Leow, S.W.; Li, W.; Tan, J.M.R.; Venkataraj, S.; Tunuguntla, V.; Zhang, M.; Magdassi, S.; Wong, L.H. Solution-Processed Semitransparent CZTS Thin-Film Solar Cells via Cation Substitution and Rapid Thermal Annealing. Sol. RRL 2021, 5, 2100131. [CrossRef]

15. Chung, S.; Cho, K.; Lee, T. Recent Progress in Inkjet-Printed Thin-Film Transistors. Adv. Sci. 2019, 6, 1801445. [CrossRef]

16. Sun, J.; Cui, B.; Chu, F.; Yun, C.; He, M.; Li, L.; Song, Y. Printable Nanomaterials for the Fabrication of High-Performance Supercapacitors. Nanomaterials 2018, 8, 528. [CrossRef]

17. Cai, G.; Darmawan, P.; Cui, M.; Wang, J.; Chen, J.; Magdassi, S.; Lee, P.S. Highly Stable Transparent Conductive Silver Grid/PEDOT: PSS Electrodes for Integrated Bifunctional Flexible Electrochromic Supercapacitors. Adv. Energy Mater. 2015, 6, 1501882. [CrossRef]

18. Kim, J.; Kumar, R.; Bandodkar, A.J.; Wang, J. Advanced Materials for Printed Wearable Electrochemical Devices: A Review. Adv. Electron. Mater. 2017, 3, 1600260. [CrossRef]

19. Ibrahim, N.; Akindoyo, J.O.; Mariatti, M. Recent Development in Silver-Based Ink for Flexible Electronics. J. Sci. Adv. Mater. Devices 2021, 7, 100395. [CrossRef]

20. Zhang, Y.; Zhu, Y.; Zheng, S.; Zhang, L.; Shi, X.; He, J.; Chou, X.; Wu, Z.-S. Ink Formulation, Scalable Applications and Challenging Perspectives of Screen Printing for Emerging Printed Microelectronics. J. Energy Chem. 2021, 63, 498-513. [CrossRef]

21. Wang, Y.; Du, D.; Zhou, Z.; Xie, H.; Li, J.; Zhao, Y. Reactive Conductive Ink Capable of In Situ and Rapid Synthesis of Conductive Patterns Suitable for Inkjet Printing. Molecules 2019, 24, 3548. [CrossRef] [PubMed]

22. Mou, Y.; Cheng, H.; Wang, H.; Sun, Q.; Liu, J.; Peng, Y.; Chen, M. Facile Preparation of Stable Reactive Silver Ink for Highly Conductive and Flexible Electrodes. Appl. Surf. Sci. 2018, 475, 75-82. [CrossRef]

23. Stempien, Z.; Rybicki, E.; Lesnikowski, J. Inkjet-Printing Deposition of Silver Electro-Conductive Layers on Textile Substrates at Low Sintering Temperature by Using an Aqueous Silver Ions-Containing Ink for Textronic Applications. Sens. Actuators B Chem. 2016, 224, 714-725. [CrossRef]

24. Kastner, J.; Faury, T.; Außerhuber, H.M.; Obermüller, T.; Leichtfried, H.; Haslinger, M.J.; Liftinger, E.; Innerlohinger, J.; Gnatiuk, I.; Holzinger, D.; et al. Silver-Based Reactive Ink for Inkjet-Printing of Conductive Lines on Textiles. Microelectron. Eng. 2017, 176, 84-88. [CrossRef]

25. He, B.; Yang, S.; Qin, Z.; Wen, B.; Zhang, C. The Roles of Wettability and Surface Tension in Droplet Formation during Inkjet Printing. Sci. Rep. 2017, 7, 11841. [CrossRef]

26. Borhan, A.; Pence, S.B.; Sporer, A.H. Mechanism of Drying of Water-Based Inks on Bond Papers. J. Imaging Technol. 1990, 16, 65-69.

27. Saad, A.A.E.-R.E.; Aydemir, C.; Özsoy, S.A.; Yenidoğan, S. Drying Methods of the Printing Inks. J. Graph. Eng. Des. 2021, 12, 29-37. [CrossRef]

28. Cano-Raya, C.; Denchev, Z.Z.; Cruz, S.F.; Viana, J.C.; Cano-Raya, C.; Denchev, Z.Z.; Cruz, S.F.; Viana, J.C. Chemistry of Solid Metal-Based Inks and Pastes for Printed Electronics-A Review. Appl. Mater. Today 2019, 15, 416-430. [CrossRef]

29. De Souza, T.A.J.; Souza, L.R.R.; Franchi, L.P. Silver Nanoparticles: An Integrated View of Green Synthesis Methods, Transformation in the Environment, and Toxicity. Ecotoxicol. Environ. Saf. 2019, 171, 691-700. [CrossRef]

30. Wei, L.; Lu, J.; Xu, H.; Patel, A.; Chen, Z.-S.; Chen, G. Silver Nanoparticles: Synthesis, Properties, and Therapeutic Applications. Drug Discov. Today 2014, 20, 595-601. [CrossRef]

31. Washio, I.; Xiong, Y.; Yin, Y.; Xia, Y. Reduction by the End Groups of Poly (Vinyl Pyrrolidone): A New and Versatile Route to the Kinetically Controlled Synthesis of Ag Triangular Nanoplates. Adv. Mater. 2006, 18, 1745-1749. [CrossRef]

32. Togashi, T.; Tsuchida, K.; Soma, S.; Nozawa, R.; Matsui, J.; Kanaizuka, K.; Kurihara, M. Size-Tunable Continuous-Seed-Mediated Growth of Silver Nanoparticles in Alkylamine Mixture via the Stepwise Thermal Decomposition of Silver Oxalate. Chem. Mater. 2020, 32, 9363-9370. [CrossRef] 
33. LaMer, V.K.; Dinegar, R.H. Theory, Production and Mechanism of Formation of Monodispersed Hydrosols. J. Am. Chem. Soc. 1950, 72, 4847-4854. [CrossRef]

34. Zhang, X.-F.; Liu, Z.-G.; Shen, W.; Gurunathan, S. Silver Nanoparticles: Synthesis, Characterization, Properties, Applications, and Therapeutic Approaches. Int. J. Mol. Sci. 2016, 17, 1534. [CrossRef] [PubMed]

35. Dong, X.; Ji, X.; Wu, H.; Zhao, L.; Li, J.; Yang, W. Shape Control of Silver Nanoparticles by Stepwise Citrate Reduction. J. Phys. Chem. C 2009, 113, 6573-6576. [CrossRef]

36. Oliveira, M.M.; Ugarte, D.; Zanchet, D.; Zarbin, A.J. Influence of synthetic parameters on the size, structure, and stability of dodecanethiol-stabilized silver nanoparticles. J. Colloid Interface Sci. 2005, 292, 429-435. [CrossRef]

37. Ajitha, B.; Reddy, Y.A.K.; Reddy, P.S.; Jeon, H.-J.; Ahn, C.W. Role of Capping Agents in Controlling Silver Nanoparticles Size, Antibacterial Activity and Potential Application as Optical Hydrogen Peroxide Sensor. RSC Adv. 2016, 6, 36171-36179. [CrossRef]

38. Lin, X.; Lin, S.; Liu, Y.; Gao, M.; Zhao, H.; Liu, B.; Hasi, W.; Wang, L. Facile Synthesis of Monodisperse Silver Nanospheres in Aqueous Solution via Seed-Mediated Growth Coupled with Oxidative Etching. Langmuir 2018, 34, 6077-6084. [CrossRef]

39. Li, N.; Yin, H.; Zhuo, X.; Yang, B.; Zhu, X.-M.; Wang, J. Infrared-Responsive Colloidal Silver Nanorods for Surface-Enhanced Infrared Absorption. Adv. Opt. Mater. 2018, 6. [CrossRef]

40. Sun, Y.; Xia, Y. Shape-Controlled Synthesis of Gold and Silver Nanoparticles. Science 2002, 298, 2176-2179. [CrossRef]

41. Tang, B.; An, J.; Zheng, X.; Xu, S.; Li, D.; Zhou, J.; Zhao, B.; Xu, W. Silver Nanodisks with Tunable Size by Heat Aging. J. Phys. Chem. C 2008, 112, 18361-18367. [CrossRef]

42. Gunasekaran, S.; Sankari, G.; Ponnusamy, S. Vibrational Spectral Investigation on Xanthine and Its Derivatives-The Ophylline, Caffeine and Theobromine. Spectrochim. Acta A 2005, 61, 117-127. [CrossRef] [PubMed]

43. Wiley, B.; Herricks, T.; Sun, Y.; Xia, Y. Polyol Synthesis of Silver Nanoparticles: Use of Chloride and Oxygen to Promote the Formation of Single-Crystal, Truncated Cubes and Tetrahedrons. Nano Lett. 2004, 4, 1733-1739. [CrossRef]

44. Wiley, B.; Xiong, Y.; Li, Z.-Y.; Yin, Y.; Xia, Y. Right Bipyramids of Silver: A New Shape Derived from Single Twinned Seeds. Nano Lett. 2006, 6, 765-768. [CrossRef] [PubMed]

45. Bryan, W.W.; Jamison, A.C.; Chinwangso, P.; Rittikulsittichai, S.; Lee, T.-C. Preparation of THPC-Generated Silver, Platinum, and Palladium Nanoparticles and their Use in the Synthesis of Ag, Pt, Pd, and Pt/Ag Nanoshells. RSC Adv. 2016, 6, 68150-68159. [CrossRef]

46. Pajor-Świerzy, A.; Szczepanowicz, K.; Kamyshny, A.; Magdassi, S. Metallic Core-Shell Nanoparticles for Conductive Coatings and Printing. Adv. Colloid Interface Sci. 2021, 299, 102578. [CrossRef]

47. Wiley, B.J.; Chen, Y.; McLellan, J.M.; Xiong, Y.; Li, Z.-Y.; Ginger, A.D.; Xia, Y. Synthesis and Optical Properties of Silver Nanobars and Nanorice. Nano Lett. 2007, 7, 1032-1036. [CrossRef]

48. Sun, Y.; Mayers, B.; Herricks, T.; Xia, Y. Crystalline Silver Nanowires by Soft Solution Processing. Nano. Lett. 2003, 3, 955-960. [CrossRef]

49. Garcia-Leis, A.; Arreba, I.R.; Sanchez-Cortes, S. Morphological Tuning of Plasmonic Silver Nanostars by Controlling the NanoParticle Growth Mechanism: Application in the SERS Detection of the Amyloid Marker Congo Red. Colloids Surf. A Physicochem. Eng. Asp. 2017, 535, 49-60. [CrossRef]

50. Reguera, J.; Langer, J.; de Aberasturi, D.J.; Liz-Marzán, L.M. Anisotropic Metal Nanoparticles for Surface Enhanced Raman Scattering. Chem. Soc. Rev. 2017, 46, 3866-3885. [CrossRef]

51. Loiseau, A.; Asila, V.; Boitel-Aullen, G.; Lam, M.; Salmain, M.; Boujday, S. Silver-Based Plasmonic Nanoparticles for and their Use in Biosensing. Biosensors 2019, 9, 78. [CrossRef] [PubMed]

52. Wiley, B.J.; Im, S.H.; Li, Z.-Y.; McLellan, J.; Siekkinen, A.; Xia, Y. Maneuvering the Surface Plasmon Resonance of Silver Nanostructures through Shape-Controlled Synthesis. J. Phys. Chem. B 2006, 110, 15666-15675. [CrossRef] [PubMed]

53. Xue, C.; Mirkin, C.A. pH-Switchable Silver Nanoprism Growth Pathways. Angew. Chem. 2007, 119, 2082-2084. [CrossRef]

54. Jiang, X.C.; Chen, W.M.; Chen, C.Y.; Xiong, S.X.; Yu, A. Role of Temperature in the Growth of Silver Nanoparticles Through a Synergetic Reduction Approach. Nanoscale Res. Lett. 2010, 6, 32-39. [CrossRef]

55. Yoo, J.; So, H.; Yang, M.; Lee, K.-J. Effect of Chloride Ion on Synthesis of Silver Nanoparticle Using Retrieved Silver Chloride as a Precursor from the Electronic Scrap. Appl. Surf. Sci. 2019, 475, 781-784. [CrossRef]

56. Zhang, Y.; Peng, H.; Huang, W.; Zhou, Y.; Yan, D. Facile Preparation and Characterization of Highly Antimicrobial Colloid Ag or Au Nanoparticles. J. Colloid Interface Sci. 2008, 325, 371-376. [CrossRef]

57. Malassis, L.; Dreyfus, R.; Murphy, R.J.; Hough, L.A.; Donnio, B.; Murray, C.B. One-Step Green Synthesis of Gold and Silver Nanoparticles with Ascorbic Acid and their Versatile Surface Post-Functionalization. RSC Adv. 2016, 6, 33092-33100. [CrossRef]

58. Leng, Z.; Wu, D.; Yang, Q.; Zeng, S.; Xia, W. Facile and One-Step Liquid Phase Synthesis of Uniform Silver Nanoparticles Reduction by Ethylene Glycol. Optik 2018, 154, 33-40. [CrossRef]

59. Sakthivel, P.; Sekar, K. A Sensitive Isoniazid Capped Silver Nanoparticles-Selective Colorimetric Fluorescent Sensor for $\mathrm{Hg}^{2+} \mathrm{Ions}$ in Aqueous Medium. J. Fluoresc. 2020, 30, 91-101. [CrossRef]

60. Sreelekha, E.; George, B.; Shyam, A.; Sajina, N.; Mathew, B. A Comparative Study on the Synthesis, Characterization, and Antioxidant Activity of Green and Chemically Synthesized Silver Nanoparticles. BioNanoScience 2021, 11, 489-496. [CrossRef]

61. Kamarudin, D.; Hashim, N.A.; Ong, B.H.; Hassan, C.R.C.; Manaf, N.A. Synthesis of Silver Nanoparticles stabilised by PVP for Polymeric Membrane Application: A Comparative Study. Mater. Technol. 2021, 1-13. [CrossRef] 
62. Waqas, M.; Zulfiqar, A.; Ahmad, H.B.; Akhtar, N.; Hussain, M.; Shafiq, Z.; Abbas, Y.; Mehmood, K.; Ajmal, M.; Yang, M. Fabrication of Highly Stable Silver Nanoparticles with Shape-Dependent Electrochemical Efficacy. Electrochim. Acta 2018, 271, 641-651. [CrossRef]

63. Makwana, B.A.; Vyas, D.J.; Bhatt, K.D.; Jain, V.K.; Agrawal, Y.K. Highly Stable Antibacterial Silver Nanoparticles as Selective Fluorescent Sensor for Fe3+ Ions. Spectrochim. Acta Part A Mol. Biomol. Spectrosc. 2015, 134, 73-80. [CrossRef] [PubMed]

64. Raza, M.A.; Kanwal, Z.; Rauf, A.; Sabri, A.N.; Riaz, S.; Naseem, S. Size- and Shape-Dependent Antibacterial Studies of Silver Nanoparticles Synthesized by Wet Chemical Routes. Nanomaterials 2016, 6, 74. [CrossRef]

65. Restrepo, C.V.; Villa, C.C. Synthesis of Silver Nanoparticles, Influence of Capping Agents, and Dependence on Size and Shape: A Review. Environ. Nanotechnol. Monit. Manag. 2021, 15, 100428. [CrossRef]

66. Martínez-Castañón, G.A.; Niño-Martínez, N.; Martínez-Gutierrez, F.; Martínez-Mendoza, J.R.; Ruiz, F. Synthesis and Antibacterial Activity of Silver Nanoparticles with Different Sizes. J. Nanopart. Res. 2008, 10, 1343-1348. [CrossRef]

67. Zhou, J.; An, J.; Tang, B.; Xu, S.; Cao, Y.; Zhao, B.; Xu, W.; Chang, J.; Lombardi, J.R. Growth of Tetrahedral Silver Nanocrystals in Aqueous Solution and their SERS Enhancement. Langmuir 2008, 24, 10407-10413. [CrossRef]

68. Guzman, M.; Dille, J.; Godet, S. Synthesis and Antibacterial Activity of Silver Nanoparticles against Gram-Positive and GramNegative Bacteria. Nanomed. Nanotechnol. Biol. Med. 2012, 8, 37-45. [CrossRef]

69. Bastús, N.G.; Merkoçi, F.; Piella, J.; Puntes, V. Synthesis of Highly Monodisperse Citrate-Stabilized Silver Nanoparticles of up to 200 nm: Kinetic Control and Catalytic Properties. Chem. Mater. 2014, 26, 2836-2846. [CrossRef]

70. Xing, L.; Xiahou, Y.; Zhang, P.; Du, W.; Xia, H. Size Control Synthesis of Monodisperse, Quasi-Spherical Silver Nanoparticles to Realize Surface-Enhanced Raman Scattering Uniformity and Reproducibility. ACS Appl. Mater. Interfaces 2019, 11, 17637-17646. [CrossRef]

71. Sosnin, I.M.; Turkov, M.N.; Shafeev, M.R.; Shulga, E.V.; Kink, I.; Vikarchuk, A.A.; Romanov, A.E. Synthesis of Silver Nanochains with a Chemical Method. Mater. Phys. Mechan 2017, 32, 198-206.

72. Halder, S.; Ahmed, A.N.; Gafur, A.; Seong, G.; Hossain, M.Z. Size-Controlled Facile Synthesis of Silver Nanoparticles by Chemical Reduction Method and Analysis of their Antibacterial Performance. ChemistrySelect 2021, 6, 9714-9720. [CrossRef]

73. Mohamad Kasim, A.S.; Ariff, A.B.; Mohamad, R.; Wong, F.W.F. Interrelations of Synthesis Method, Polyethylene Glycol Coating, Physico-Chemical Characteristics, and Antimicrobial Activity of Silver Nanoparticles. Nanomaterials 2020, 10, 2475. [CrossRef] [PubMed]

74. Elnaggar, M.; Emam, H.; Fathalla, M.; Abdel-Aziz, M.; Zahran, M. Chemical Synthesis of Silver Nanoparticles in Its Solid State: Highly Efficient Antimicrobial Cotton Fabrics for Wound Healing Properties. Egypt. J. Chem. 2021, 64, 2697-2709. [CrossRef]

75. Mendrek, B.; Chojniak, J.; Libera, M.; Trzebicka, B.; Bernat, P.; Paraszkiewicz, K.; Płaza, G. Silver Nanoparticles Formed in bio-and chemical syntheses with biosurfactant as the stabilizing agent. J. Dispers. Sci. Technol. 2017, 38, 1647-1655. [CrossRef]

76. Vazquez-Muñoz, R.; Arellano-Jimenez, M.J.; Lopez, F.D.; Lopez-Ribot, J.L. Protocol optimization for a fast, simple and Economical Chemical Reduction Synthesis of Antimicrobial Silver Nanoparticles in Non-Specialized Facilities. BMC Res. Notes 2019, 12, 773. [CrossRef]

77. Skiba, M.; Pivovarov, A.; Makarova, A.; Vorobyova, V. Plasma-chemical Synthesis of Silver Nanoparticles in the Presence of Citrate. Chem. J. Mold. 2018, 13, 7-14. [CrossRef]

78. Aguirre, D.P.R.; Loyola, E.F.; Salcido, N.M.D.L.F.; Sifuentes, L.R.; Moreno, A.R.; Marszalek, J.E. Comparative Antibacterial Potential of Silver Nanoparticles Prepared via Chemical and Biological Synthesis. Arab. J. Chem. 2020, 13, 8662-8670. [CrossRef]

79. Shah, A.; Hussain, I.; Murtaza, G. Chemical Synthesis and Characterization of Chitosan/Silver Nanocomposites Films and their Potential Antibacterial Activity. Int. J. Biol. Macromol. 2018, 116, 520-529. [CrossRef]

80. Huang, C.-C.; Chen, H.-J.; Leong, Q.L.; Lai, W.K.; Hsu, C.-Y.; Chen, J.-C.; Huang, C.-L. Synthesis of Silver Nanoplates with a Narrow LSPR Band for Chemical Sensing through a Plasmon-Mediated Process Using Photochemical Seeds. Materialia 2021, 21, 101279. [CrossRef]

81. Jayaramudu, T.; Raghavendra, G.M.; Varaprasad, K.; Reddy, G.V.S.; Reddy, A.B.; Sudhakar, K.; Sadiku, E.R. Preparation and Characterization of Poly (ethylene Glycol) Stabilized Nano Silver Particles by a Mechanochemical Assisted Ball Mill Process. J. Appl. Polym. Sci. 2015, 133. [CrossRef]

82. Zhang, H.; Zou, G.; Liu, L.; Tong, H.; Li, Y.; Bai, H.; Wu, A. Synthesis of Silver Nanoparticles Using Large-Area Arc Discharge and Its Application in Electronic Packaging. J. Mater. Sci. 2016, 52, 3375-3387. [CrossRef]

83. Mafuné, F.; Kohno, J.-Y.; Takeda, Y.; Kondow, T.; Sawabe, H. Formation and Size Control of Silver Nanoparticles by Laser Ablation in Aqueous Solution. J. Phys. Chem. B 2000, 104, 9111-9117. [CrossRef]

84. Munkhbayar, B.; Tanshen, R.; Jeoun, J.; Chung, H.; Jeong, H. Surfactant-Free Dispersion of Silver Nanoparticles into MWCNTAqueous Nanofluids Prepared by One-Step Technique and their Thermal Characteristics. Ceram. Int. 2013, 39, 6415-6425. [CrossRef]

85. Hwang, J.S.; Park, J.-E.; Kim, G.W.; Nam, H.; Yu, S.; Jeon, J.S.; Kim, S.; Lee, H.; Yang, M. Recycling Silver Nanoparticle Debris from Laser Ablation of Silver Nanowire in Liquid Media toward Minimum Material Waste. Sci. Rep. 2021, 11, 2262. [CrossRef]

86. El-Khatib, A.M.; Badawi, M.S.; Ghatass, Z.F.; Mohamed, M.M.; El-Khatib, M. Synthesize of Silver Nanoparticles by Arc Discharge Method Using Two Different Rotational Electrode Shapes. J. Clust. Sci. 2018, 29, 1169-1175. [CrossRef]

87. Nancy, P.; James, J.; Valluvadasan, S.; Kumar, R.A.; Kalarikkal, N. Laser-Plasma Driven Green Synthesis of Size Controlled Silver Nanoparticles in Ambient Liquid. Nano-Struct. Nano-Objects 2018, 16, 337-346. [CrossRef] 
88. Menazea, A. Femtosecond Laser Ablation-Assisted Synthesis of Silver Nanoparticles in Organic and Inorganic Liquids Medium and their Antibacterial Efficiency. Radiat. Phys. Chem. 2019, 168, 108616. [CrossRef]

89. Galindo, D.O.O. Silver Nanoparticles by Laser Ablation Confined in Alcohol Using an Argon Gas Environment. J. Laser Micro/Nanoeng. 2016, 11, 158-163. [CrossRef]

90. Park, S.; Her, J.; Cho, D.; Haque, M.; Park, J.H.; Lee, C.S. Preparation of Conductive Nanoink Using Pulsed-Wire-Evaporated Copper Nanoparticles for Inkjet Printing. Mater. Trans. 2012, 53, 1502-1506. [CrossRef]

91. Song, J.-W.; Lee, D.-J.; Yılmaz, F.; Hong, S.-J. Effect of Variation in Voltage on the Synthesis of Ag Nanopowder by Pulsed Wire Evaporation. J. Nanomater. 2012, 2012, 24. [CrossRef]

92. Chung, W.-H.; Hwang, Y.-T.; Lee, S.-H.; Kim, H.-S. Electrical Wire Explosion Process of Copper/Silver Hybrid Nano-Particle Ink and Its Sintering via Flash White Light to Achieve High Electrical Conductivity. Nanotechnology 2016, 27, 205704. [CrossRef] [PubMed]

93. Nayak, L.; Mohanty, S.; Nayak, S.K.; Ramadoss, A. A Review on Inkjet Printing of Nanoparticle Inks for Flexible Electronics J. Mater. Chem. C 2019, 7, 8771-8795. [CrossRef]

94. Rafique, M.; Sadaf, I.; Rafique, M.S.; Tahir, M.B. A Review on Green Synthesis of Silver Nanoparticles and their Applications. Artif. Cells Nanomed. Biotechnol. 2017, 45, 1272-1291. [CrossRef]

95. Ahmed, S.; Ahmad, M.; Swami, B.L.; Ikram, S. A Review on Plants Extract Mediated Synthesis of Silver Nanoparticles for Antimicrobial Applications: A Green Expertise. J. Adv. Res. 2015, 7, 17-28. [CrossRef]

96. Dhand, V.; Soumya, L.; Bharadwaj, S.; Chakra, S.; Bhatt, D.; Sreedhar, B. Green Synthesis of Silver Nanoparticles Using Coffea Arabica Seed Extract and its Antibacterial Activity. Mater. Sci. Eng. C 2016, 58, 36-43. [CrossRef]

97. Kumar, D.A.; Palanichamy, V.; Roopan, S.M. Green Synthesis of Silver Nanoparticles Using Alternanthera Dentata Leaf Extract at Room Temperature and their Antimicrobial Activity. Spectrochim. Acta Part A Mol. Biomol. Spectrosc. 2014, 127, 168-171. [CrossRef]

98. Anandan, M.; Poorani, G.; Boomi, P.; Varunkumar, K.; Anand, K.; Chuturgoon, A.A.; Saravanan, M.; Prabu, H.G. Green Synthesis of Anisotropic Silver Nanoparticles from the Aqueous Leaf Extract of Dodonaea Viscosa with their Antibacterial and Anticancer Activities. Process Biochem. 2019, 80, 80-88. [CrossRef]

99. Hasnain, M.S.; Javed, N.; Alam, S.; Rishishwar, P.; Rishishwar, S.; Ali, S.; Nayak, A.K.; Beg, S. Purple Heart Plant Leaves Extract-Mediated Silver Nanoparticle Synthesis: Optimization by Box-Behnken Design. Mater. Sci. Eng. C 2019, 99, 1105-1114. [CrossRef]

100. Kalaiselvi, D.; Mohankumar, A.; Shanmugam, G.; Nivitha, S.; Sundararaj, P. Green Synthesis of Silver Nanoparticles Using Latex Extract of Euphorbia Tirucalli: A Novel Approach for the Management of Root Knot Nematode, Meloidogyne Incognita. Crop. Prot. 2018, 117, 108-114. [CrossRef]

101. Tripathi, D.; Modi, A.; Narayan, G.; Rai, S.P. Green and Cost Effective Synthesis of Silver Nanoparticles from Endangered Medicinal Plant Withania Coagulans and their Potential Biomedical Properties. Mater. Sci. Eng. C 2019, 100, 152-164. [CrossRef] [PubMed]

102. Ramesh, A.; Devi, D.R.; Battu, G.; Basavaiah, K. A Facile Plant Mediated Synthesis of Silver Nanoparticles Using an Aqueous Leaf Extract of Ficus Hispida Linn. f. for Catalytic, Antioxidant and Antibacterial Applications. S. Afr. J. Chem. Eng. 2018, 26, 25-34. [CrossRef]

103. Arokiyaraj, S.; Vincent, S.; Saravanan, M.; Lee, Y.; Oh, Y.K.; Kim, K.H. Green Synthesis of Silver Nanoparticles Using Rheum Palmatum Root extract and their Antibacterial Activity against Staphylococcus Aureus and Pseudomonas Aeruginosa. Artif. Cells Nanomed. Biotechnol. 2016, 45, 372-379. [CrossRef] [PubMed]

104. Yazdi, M.E.T.; Amiri, M.S.; Hosseini, H.A.; Oskuee, R.K.; Mosawee, H.; Pakravanan, K.; Darroudi, M. Plant-Based Synthesis of Silver Nanoparticles in Handelia Trichophylla and their Biological Activities. Bull. Mater. Sci. 2019, 42, 155. [CrossRef]

105. Alsammarraie, F.K.; Wang, W.; Zhou, P.; Mustapha, A.; Lin, M. Green synthesis of silver nanoparticles using turmeric extracts and investigation of their antibacterial activities. Colloids Surfaces B Biointerfaces 2018, 171, 398-405. [CrossRef] [PubMed]

106. Zuorro, A.; Iannone, A.; Natali, S.; Lavecchia, R. Green Synthesis of Silver Nanoparticles Using Bilberry and Red Currant Waste Extracts. Processes 2019, 7, 193. [CrossRef]

107. Rolim, W.R.; Pelegrino, M.T.; Lima, B.D.A.; Ferraz, L.S.; Costa, F.N.; Bernardes, J.S.; Rodigues, T.; Brocchi, M.; Seabra, A.B. Green Tea Extract Mediated Biogenic Synthesis of Silver Nanoparticles: Characterization, Cytotoxicity Evaluation and Antibacterial Activity. Appl. Surf. Sci. 2018, 463, 66-74. [CrossRef]

108. Aygun, A.; Özdemir, S.; Gülcan, M.; Cellat, K.; Şen, F. Synthesis and Characterization of Reishi Mushroom-Mediated Green Synthesis of Silver Nanoparticles for the Biochemical Applications. J. Pharm. Biomed. Anal. 2019, 178, 112970. [CrossRef]

109. Paosen, S.; Saising, J.; Septama, A.W.; Voravuthikunchai, S.P. Green Synthesis of Silver Nanoparticles Using Plants from Myrtaceae Family and Characterization of their Antibacterial Activity. Mater. Lett. 2017, 209, 201-206. [CrossRef]

110. Sharma, V.; Kaushik, S.; Pandit, P.; Dhull, D.; Yadav, J.P.; Kaushik, S. Green Synthesis of Silver Nanoparticles from Medicinal Plants and Evaluation of their Antiviral Potential against Chikungunya Virus. Appl. Microbiol. Biotechnol. 2018, 103, 881-891. [CrossRef]

111. Meva, F.E.; Mbeng, J.O.A.; Ebongue, C.O.; Schlüsener, C.; Kökçam-Demir, Ü.; Ntoumba, A.A.; Kedi, P.B.E.; Elanga, E.; Loudang, E.-R.N.; Nko'O, M.H.J.; et al. Stachytarpheta Cayennensis Aqueous Extract, a New Bioreactor towards Silver Nanoparticles for Biomedical Applications. J. Biomater. Nanobiotechnol. 2019, 10, 102-119. [CrossRef] 
112. AlSalhi, M.; Elangovan, K.; Ranjitsingh, A.J.A.; Murali, P.; Devanesan, S. Synthesis of Silver Nanoparticles Using Plant Derived 4-N-Methyl Benzoic Acid and Evaluation of Antimicrobial, Antioxidant and Antitumor Activity. Saudi J. Biol. Sci. 2019, 26, 970-978. [CrossRef] [PubMed]

113. Manosalva, N.; Tortella, G.; Diez, M.C.; Schalchli, H.; Seabra, A.B.; Durán, N.; Rubilar, O. Green Synthesis of Silver Nanoparticles: Effect of Synthesis Reaction Parameters on Antimicrobial Activity. World J. Microbiol. Biotechnol. 2019, 35, 88. [CrossRef] [PubMed]

114. Salaheldin, T.A.; El-Chaghaby, G.; El-Sherbiny, M.A. Green Synthesis of Silver Nanoparticles Using Portulacaria Afra Plant Extract: Characterization and Evaluation of its Antibacterial, Anticancer Activities. Nov. Res. Microbiol. J. 2019, 3, $215-222$. [CrossRef]

115. Lakshmanan, G.; Sathiyaseelan, A.; Kalaichelvan, P.T.; Murugesan, K. Plant-Mediated Synthesis of Silver Nanoparticles Using Fruit Extract of Cleome Viscosa, L.: Assessment of their Antibacterial and Anticancer Activity. Karbala Int. J. Mod. Sci. 2018, 4, 61-68. [CrossRef]

116. Shaik, M.R.; Khan, M.; Kuniyil, M.; Al-Warthan, A.; Alkhathlan, H.Z.; Siddiqui, M.R.H.; Shaik, J.P.; Ahamed, A.; Mahmood, A.; Khan, M.; et al. Plant-Extract-Assisted Green Synthesis of Silver Nanoparticles Using Origanum vulgare L. Extract and Their Microbicidal Activities. Sustainability 2018, 10, 913. [CrossRef]

117. Salary, R.; Lombardi, J.P.; Tootooni, M.S.; Donovan, R.; Rao, P.K.; Borgesen, P.; Poliks, M.D. Computational Fluid Dynamics Modeling and Online Monitoring of Aerosol Jet Printing Process. J. Manuf. Sci. Eng. 2016, 139, 021015. [CrossRef]

118. Shen, W.; Zhang, X.; Huang, Q.; Xu, Q.; Song, W. Preparation of Solid Silver Nanoparticles for Inkjet Printed Flexible Electronics with High Conductivity. Nanoscale 2013, 6, 1622-1628. [CrossRef]

119. Shahariar, H.; Kim, I.; Soewardiman, H.; Jur, J.S. Inkjet Printing of Reactive Silver Ink on Textiles. ACS Appl. Mater. Interfaces 2019, 11, 6208-6216. [CrossRef]

120. Zope, K.R.; Cormier, D.; Williams, S.A. Reactive Silver Oxalate Ink Composition with Enhanced Curing Conditions for Flexible Substrates. ACS Appl. Mater. Interfaces 2018, 10, 3830-3837. [CrossRef]

121. Hyun, W.J.; Lim, S.; Ahn, B.Y.; Lewis, J.A.; Frisbie, C.D.; Francis, L.F. Screen Printing of Highly Loaded Silver Inks on Plastic Substrates Using Silicon Stencils. ACS Appl. Mater. Interfaces 2015, 7, 12619-12624. [CrossRef] [PubMed]

122. Wang, Z.; Wang, W.; Jiang, Z.; Yu, D. Low Temperature Sintering Nano-Silver Conductive Ink Printed on Cotton Fabric as Printed Electronics. Prog. Org. Coat. 2016, 101, 604-611. [CrossRef]

123. Kell, A.J.; Paquet, C.; Mozenson, O.; Djavani-Tabrizi, I.; Deore, B.; Liu, X.; Lopinski, G.P.; James, R.; Hettak, K.; Shaker, J.; et al Versatile Molecular Silver Ink Platform for Printed Flexible Electronics. ACS Appl. Mater. Interfaces 2017, 9, 17226-17237. [CrossRef] [PubMed]

124. Cheon, J.M.; Lee, J.H.; Song, Y.; Kim, J. Synthesis of Ag Nanoparticles Using an Electrolysis Method and Application to Inkjet Printing. Colloids Surf. A Physicochem. Eng. Asp. 2011, 389, 175-179. [CrossRef]

125. Kosmala, A.; Wright, R.; Zhang, Q.; Kirby, P. Synthesis of Silver Nano Particles and Fabrication of Aqueous Ag Inks for Inkjet Printing. Mater. Chem. Phys. 2011, 129, 1075-1080. [CrossRef]

126. Chen, C.; Dong, T.-Y.; Chang, T.; Chen, M.; Chen, H.; Chen, I. Using Nanoparticles as Direct-Injection Printing Ink to Fabricate Conductive Silver Features on a Transparent Flexible PET Substrate at Room Temperature. Acta Mater. 2012, 60, 5914-5924 [CrossRef]

127. Jung, I.; Jo, Y.H.; Kim, I.; Lee, H.M. A Simple Process for Synthesis of Ag Nanoparticles and Sintering of Conductive Ink for Use in Printed Electronics. J. Electron. Mater. 2011, 41, 115-121. [CrossRef]

128. Tung, H.-T.; Chen, I.-G.; Kempson, I.M.; Song, J.-M.; Liu, Y.-F.; Chen, P.-W.; Hwang, W.-S.; Hwu, Y. Shape-Controlled Synthesis of Silver Nanocrystals by X-ray Irradiation for Inkjet Printing. ACS Appl. Mater. Interfaces 2012, 4, 5930-5935. [CrossRef]

129. Novara, C.; Petracca, F.; Virga, A.; Rivolo, P.; Ferrero, S.; Chiolerio, A.; Geobaldo, F.; Porro, S.; Giorgis, F. SERS Active Silver Nanoparticles Synthesized by Inkjet Printing on Mesoporous Silicon. Nanoscale Res. Lett. 2014, 9, 527. [CrossRef]

130. Zhang, N.; Luo, J.; Liu, R.; Liu, X. Tannic Acid Stabilized Silver Nanoparticles for Inkjet Printing of Conductive Flexible Electronics. RSC Adv. 2016, 6, 83720-83729. [CrossRef]

131. Liu, Z.; Ji, H.; Wang, S.; Zhao, W.; Huang, Y.; Feng, H.; Wei, J.; Li, M. Enhanced Electrical and Mechanical Properties of a Printed Bimodal Silver Nanoparticle Ink for Flexible Electronics. Phys. Status Solidi A 2018, 215, 1800007. [CrossRef]

132. Barrera, N.; Guerrero, L.; Debut, A.; Santa-Cruz, P. Printable Nanocomposites of Polymers and Silver Nanoparticles for Antibacterial Devices Produced by DoD Technology. PLoS ONE 2018, 13, e0200918. [CrossRef]

133. Trinh, D.C.; Dang, T.M.D.; Tran, K.H.; Dang, M.C. Preparation of Conductive Ink Based on Silver Nanoparticles. Adv. Nat. Sci. Nanosci. Nanotechnol. 2019, 10, 045007. [CrossRef]

134. Hao, Y.; Gao, J.; Xu, Z.; Zhang, N.; Luo, J.; Liu, X. Preparation of Silver Nanoparticles with Hyperbranched Polymers as a Stabilizer for Inkjet Printing of Flexible Circuits. New J. Chem. 2019, 43, 2797-2803. [CrossRef]

135. Yang, W.; Mathies, F.; Unger, E.L.; Hermerschmidt, F.; List-Kratochvil, E.J.W. One-Pot Synthesis of a Stable and Cost-Effective Silver Particle-Free Ink for Inkjet-Printed Flexible Electronics. J. Mater. Chem. C 2020, 8, 16443-16451. [CrossRef]

136. Jadav, J.K.; Umrania, V.V.; Rathod, K.J.; Golakiya, B.A. Development of Silver/Carbon Screen-Printed Electrode for Rapid Determination of Vitamin C from Fruit Juices. LWT 2018, 88, 152-158. [CrossRef]

137. Liu, L.; Wan, X.; Sun, L.; Yang, S.; Dai, Z.; Tian, Q.; Lei, M.; Xiao, X.; Jiang, C.; Wu, W. Anion-Mediated Synthesis of Monodisperse Silver Nanoparticles Useful for Screen Printing of High-Conductivity Patterns on Flexible Substrates for Printed Electronics. RSC Adv. 2014, 5, 9783-9791. [CrossRef] 
138. Ding, J.; Liu, J.; Tian, Q.; Wu, Z.; Yao, W.; Dai, Z.; Liu, L.; Wu, W. Preparing of Highly Conductive Patterns on Flexible Substrates by Screen Printing of Silver Nanoparticles with Different Size Distribution. Nanoscale Res. Lett. 2016, 11, 412. [CrossRef]

139. Shankar, R.; Groven, L.; Amert, A.; Whites, K.W.; Kellar, J.J. Non-Aqueous Synthesis of Silver Nanoparticles Using Tin Acetate as a Reducing Agent for the Conductive Ink Formulation in Printed Electronics. J. Mater. Chem. 2011, 21, 10871-10877. [CrossRef]

140. Ivanov, V.V.; Efimov, A.A.; Myl'Nikov, D.A.; Lizunova, A.A. Synthesis of Nanoparticles in a Pulsed-Periodic Gas Discharge and Their Potential Applications. Russ. J. Phys. Chem. A 2018, 92, 607-612. [CrossRef]

141. Sonawane, A.; Mujawar, M.A.; Bhansali, S. Effects of Cold Atmospheric Plasma Treatment on the Morphological and Optical Properties of Plasmonic Silver Nanoparticles. Nanotechnology 2020, 31, 365706. [CrossRef] [PubMed]

142. Wünscher, S.; Abbel, R.; Perelaer, J.; Schubert, U.S. Progress of Alternative Sintering Approaches of Inkjet-Printed Metal Inks and their Application for Manufacturing of Flexible Electronic Devices. J. Mater. Chem. C 2014, 2, 10232-10261. [CrossRef]

143. $\mathrm{Wu}, \mathrm{W}$. Inorganic Nanomaterials for Printed Electronics: A Review. Nanoscale 2017, 9, 7342-7372. [CrossRef]

144. Yang, W.; Wang, C.; Arrighi, V. An Organic Silver Complex Conductive Ink Using Both Decomposition and Self-Reduction Mechanisms in Film Formation. J. Mater. Sci. Mater. Electron. 2017, 29, 2771-2783. [CrossRef]

145. Sazan, H.; Piperno, S.; Layani, M.; Magdassi, S.; Shpaisman, H. Directed Assembly of Nanoparticles into Continuous Microstructures by Standing Surface Acoustic Waves. J. Colloid Interface Sci. 2018, 536, 701-709. [CrossRef] [PubMed]

146. Rezaga, B.F.Y.; Balela, M.D.L. Sintering of Silver Nanoparticles at Room-Temperature for Conductive Ink Applications. Key Eng. Mater. 2018, 775, 144-148. [CrossRef]

147. Wakuda, D.; Hatamura, M.; Suganuma, K. Novel Method for Room Temperature Sintering of Ag Nanoparticle Paste in Air. Chem. Phys. Lett. 2007, 441, 305-308. [CrossRef]

148. Wakuda, D.; Kim, K.-S.; Suganuma, K. Room-Temperature Sintering Process of Ag Nanoparticle Paste. IEEE Trans. Compon. Packag. Technol. 2009, 32, 627-632. [CrossRef]

149. Grouchko, M.; Kamyshny, A.; Mihailescu, C.F.; Anghel, D.F.; Magdassi, S. Conductive Inks with a “Built-In” Mechanism That Enables Sintering at Room Temperature. ACS Nano 2011, 5, 3354-3359. [CrossRef]

150. Allen, M.; Alastalo, A.; Suhonen, M.; Mattila, T.; Leppäniemi, J.; Seppa, H. Contactless Electrical Sintering of Silver Nanoparticles on Flexible Substrates. IEEE Trans. Microw. Theory Tech. 2011, 59, 1419-1429. [CrossRef]

151. Roberson, D.; Wicker, R.; Macdonald, E. Ohmic Curing of Printed Silver Conductive Traces. J. Electron. Mater. 2012, 41, 2553-2566. [CrossRef]

152. Hummelgård, M.; Zhang, R.; Nilsson, H.-E.; Olin, H. Electrical Sintering of Silver Nanoparticle Ink Studied by In-Situ TEM Probing. PLoS ONE 2011, 6, e17209. [CrossRef] [PubMed]

153. Moon, S.-J. The Effect of Temperature on the Electrical Properties of Inkjet-Printed Silver Nanoparticle Ink during Electrical Sintering. J. Nanosci. Nanotechnol. 2013, 13, 6174-6178. [CrossRef] [PubMed]

154. Lee, H.; Kim, D.; Lee, I.; Moon, Y.-J.; Hwang, J.-Y.; Park, K.; Moon, S.-J. Stepwise Current Electrical Sintering Method for Inkjet-Printed Conductive Ink. Jpn. J. Appl. Phys. 2014, 53, 05HC07. [CrossRef]

155. Mo, L.; Guo, Z.; Yang, L.; Zhang, Q.; Fang, Y.; Xin, Z.; Chen, Z.; Hu, K.; Han, L.; Li, L. Silver Nanoparticles Based Ink with Moderate Sintering in Flexible and Printed Electronics. Int. J. Mol. Sci. 2019, 20, 2124. [CrossRef]

156. Hong, S.; Yeo, J.; Kim, G.; Kim, D.; Lee, H.; Kwon, J.; Lee, H.; Lee, P.; Ko, S.H. Nonvacuum, Maskless Fabrication of a Flexible Metal Grid Transparent Conductor by Low-Temperature Selective Laser Sintering of Nanoparticle Ink. ACS Nano 2013, 7, 5024-5031. [CrossRef]

157. Theodorakos, I.; Zacharatos, F.; Geremia, R.; Karnakis, D.; Zergioti, I. Selective Laser Sintering of Ag Nanoparticles Ink for Applications in Flexible Electronics. Appl. Surf. Sci. 2015, 336, 157-162. [CrossRef]

158. Alshammari, A.S.; Alenezi, M.R.; Silva, S. Excimer Laser Sintereing of Silver Nanoparticles Electrodes for Fully Solution Processed Organic Thin Film Transistors. Opt. Laser Technol. 2019, 120, 105758. [CrossRef]

159. Sowade, E.; Kang, H.; Mitra, K.Y.; Weiß, O.J.; Weber, J.; Baumann, R.R. Roll-to-Roll Infrared (IR) Drying and Sintering of an Inkjet-Printed Silver Nanoparticle Ink within 1 Second. J. Mater. Chem. C 2015, 3, 11815-11826. [CrossRef]

160. Park, J.; Kang, H.J.; Shin, K.-H.; Kang, H. Fast Sintering of Silver Nanoparticle and Flake Layers by Infrared Module Assistance in Large Area Roll-to-Roll Gravure Printing System. Sci. Rep. 2016, 6, 34470. [CrossRef]

161. Kwak, J.H.; Chun, S.J.; Shon, C.-H.; Jung, S. Back-Irradiation Photonic Sintering for Defect-Free High-Conductivity Metal Patterns on Transparent Plastic. Appl. Phys. Lett. 2018, 112, 153103. [CrossRef]

162. Wünscher, S.; Stumpf, S.; Teichler, A.; Pabst, O.; Perelaer, J.; Beckert, E.; Schubert, U.S. Localized Atmospheric Plasma Sintering of Inkjet Printed Silver Nanoparticles. J. Mater. Chem. 2012, 22, 24569-24576. [CrossRef]

163. Reinhold, I.; Hendriks, C.E.; Eckardt, R.; Kranenburg, J.M.; Perelaer, J.; Baumann, R.R.; Schubert, U.S. Argon Plasma Sintering of Inkjet Printed Silver Tracks on Polymer Substrates. J. Mater. Chem. 2009, 19, 3384-3388. [CrossRef]

164. Perelaer, J.; Jani, R.; Grouchko, M.; Kamyshny, A.; Magdassi, S.; Schubert, U.S. Plasma and Microwave Flash Sintering of a Tailored Silver Nanoparticle Ink, Yielding 60\% Bulk Conductivity on Cost-Effective Polymer Foils. Adv. Mater. 2012, 24, 3993-3998. [CrossRef]

165. Wünscher, S.; Stumpf, S.; Perelaer, J.; Schubert, U.S. Towards Single-Pass Plasma Sintering: Temperature Influence of Atmospheric Pressure Plasma Sintering of Silver Nanoparticle Ink. J. Mater. Chem. C 2013, 2, 1642-1649. [CrossRef]

166. Ma, S.; Bromberg, V.; Liu, L.; Egitto, F.D.; Chiarot, P.R.; Singler, T.J. Low Temperature Plasma Sintering of Silver Nanoparticles. Appl. Surf. Sci. 2014, 293, 207-215. [CrossRef] 